\title{
Remarks on some coupled fixed point theorems in $G$-metric spaces
}

\author{
Ravi P Agarwal ${ }^{1,2}$ and Erdal Karapınar ${ }^{3 *}$
}

"Correspondence: erdalkarapinar@yahoo.com; ekarapinar@atilim.edu.tr ${ }^{3}$ Department of Mathematics, Atilim University, Incek, Ankara, 06836, Turkey

Full list of author information is available at the end of the article

\begin{abstract}
In this paper, we show that, unexpectedly, most of the coupled fixed point theorems in the context of (ordered) $\mathrm{G}$-metric spaces are in fact immediate consequences of usual fixed point theorems that are either well known in the literature or can be obtained easily.
\end{abstract}

MSC: $47 \mathrm{H} 10 ; 54 \mathrm{H} 25$

Keywords: coupled fixed point; fixed point; ordered set; metric space

\section{Introduction}

Investigation of the existence and uniqueness of fixed points of certain mappings in the framework of metric spaces is one of the centers of interests in nonlinear functional analysis. The Banach contraction mapping principle [1] is the limelight result in this direction: A self mapping $T$ on a complete metric space $(X, d)$ has a unique fixed point if there exists $0 \leq k<1$ such that $d(T x, T y)=k d(x, y)$ for all $x, y \in X$. Fixed point theory has a wide application in almost all fields of quantitative sciences such as economics, biology, physics, chemistry, computer science and many branches of engineering. It is quite natural to consider various generalizations of metric spaces in order to address the needs of these quantitative sciences. In this respect quasi-metric spaces, ultra-metric spaces, uniform spaces, fuzzy metric spaces, partial metric spaces, cone metric spaces and $b$-metric spaces can be listed as well-known examples (see e.g. [2-6]). Consequently, the concept of a G-metric space was introduced by Mustafa and Sims [7] in 2004. The authors discussed the topological properties of this space and proved the analog of the Banach contraction mapping principle in the context of $G$-metric spaces (see e.g. [8-15]).

On the other hand, Ran and Reuring [16] proved the existence and uniqueness of a fixed point of a contraction mapping in partially ordered complete metric spaces. Following this initial work, a number of authors have investigated fixed points of various mappings and their applications in the theory of differential equations (see, e.g., [17-35]). Afterwords, Gnana-Bhaskar and Lakshmikantham [22] proved the existence and uniqueness of a coupled fixed point (defined by Guo and Laksmikantham [36]) in the context of partially ordered metric spaces by introducing the notion of mixed monotone property. In this remarkable paper, Gnana-Bhaskar and Lakshmikantham [22] also gave some applications related to the existence and uniqueness of a solution of periodic boundary value problems. Following this trend, many authors have studied the (common) coupled fixed points (see, e.g., [17-28, 31, 37-47]).

(c) 2013 Agarwal and Karapınar; licensee Springer. This is an Open Access article distributed under the terms of the Creative Commons Attribution License (http://creativecommons.org/licenses/by/2.0), which permits unrestricted use, distribution, and reproduction in any medium, provided the original work is properly cited. 
In this paper, we show that, unexpectedly, most of the coupled fixed point theorems in the context of (ordered) $G$-metric spaces are in fact immediate consequences of wellknown fixed point theorems in the literature.

\section{Preliminaries}

We start with basic definitions and a detailed overview of the essential results developed in the interesting works mentioned above. Throughout this paper, $\mathbb{N}$ is the set of nonnegative integers, and $\mathbb{N}^{*}$ is the set of positive integers.

Definition 2.1 (See [7]) Let $X$ be a nonempty set and $G: X \times X \times X \rightarrow \mathbb{R}^{+}$be a function satisfying the following properties:

(G1) $G(x, y, z)=0$ if $x=y=z$,

(G2) $0<G(x, x, y)$ for all $x, y \in X$ with $x \neq y$,

(G3) $G(x, x, y) \leq G(x, y, z)$ for all $x, y, z \in X$ with $y \neq z$,

(G4) $G(x, y, z)=G(x, z, y)=G(y, z, x)=\cdots$ (symmetry in all three variables),

(G5) $G(x, y, z) \leq G(x, a, a)+G(a, y, z)$ for all $x, y, z, a \in X$ (rectangle inequality).

Then the function $G$ is called a generalized metric or, more specially, a $G$-metric on $X$, and the pair $(X, G)$ is called a $G$-metric space.

Every $G$-metric on $X$ defines a metric $d_{G}$ on $X$ by

$$
d_{G}(x, y)=G(x, y, y)+G(y, x, x), \quad \text { for all } x, y \in X .
$$

Example 2.1 Let $(X, d)$ be a metric space. The function $G: X \times X \times X \rightarrow[0,+\infty)$, defined as

$$
G(x, y, z)=\max \{d(x, y), d(y, z), d(z, x)\}
$$

or

$$
G(x, y, z)=d(x, y)+d(y, z)+d(z, x)
$$

for all $x, y, z \in X$, is a $G$-metric on $X$.

Definition 2.2 (See [7]) Let $(X, G)$ be a $G$-metric space, and let $\left\{x_{n}\right\}$ be a sequence of points of $X$. We say that $\left\{x_{n}\right\}$ is $G$-convergent to $x \in X$ if

$$
\lim _{n, m \rightarrow+\infty} G\left(x, x_{n}, x_{m}\right)=0,
$$

that is, for any $\varepsilon>0$, there exists $N \in \mathbb{N}$ such that $G\left(x, x_{n}, x_{m}\right)<\varepsilon$ for all $n, m \geq N$. We call $x$ the limit of the sequence and write $x_{n} \rightarrow x$ or $\lim _{n \rightarrow+\infty} x_{n}=x$.

Proposition 2.1 (See [7]) Let $(X, G)$ be a G-metric space. The following are equivalent:

(1) $\left\{x_{n}\right\}$ is G-convergent to $x$,

(2) $G\left(x_{n}, x_{n}, x\right) \rightarrow 0$ as $n \rightarrow+\infty$,

(3) $G\left(x_{n}, x, x\right) \rightarrow 0$ as $n \rightarrow+\infty$,

(4) $G\left(x_{n}, x_{m}, x\right) \rightarrow 0$ as $n, m \rightarrow+\infty$. 
Definition 2.3 (See [7]) Let $(X, G)$ be a $G$-metric space. A sequence $\left\{x_{n}\right\}$ is called a $G$ Cauchy sequence if, for any $\varepsilon>0$, there is $N \in \mathbb{N}$ such that $G\left(x_{n}, x_{m}, x_{l}\right)<\varepsilon$ for all $m, n, l \geq$ $N$, that is, $G\left(x_{n}, x_{m}, x_{l}\right) \rightarrow 0$ as $n, m, l \rightarrow+\infty$.

Proposition 2.2 (See [7]) Let $(X, G)$ be a G-metric space. Then the following are equivalent:

(1) the sequence $\left\{x_{n}\right\}$ is G-Cauchy,

(2) for any $\varepsilon>0$, there exists $N \in \mathbb{N}$ such that $G\left(x_{n}, x_{m}, x_{m}\right)<\varepsilon$ for all $m, n \geq N$.

Definition 2.4 (See [7]) A $G$-metric space $(X, G)$ is called $G$-complete if every $G$-Cauchy sequence is $G$-convergent in $(X, G)$.

We will use the following result which can be easily derived from the definition of Gmetric space (see, e.g., [7]).

Lemma 2.1 Let $(X, G)$ be a G-metric space. Then

$$
G(x, x, y) \leq 2 G(x, y, y) \quad \text { for all } x, y \in X
$$

Definition 2.5 (See [7]) Let $(X, G)$ be a $G$-metric space. A mapping $T: X \rightarrow X$ is said to be $G$-continuous if $\left\{T\left(x_{n}\right)\right\}$ is $G$-convergent to $T(x)$ where $\left\{x_{n}\right\}$ is any $G$-convergent sequence converging to $x$.

We characterize this definition for a mapping $F: X \times X \rightarrow X$. A mapping $F: X \times X \rightarrow X$ is said to be continuous if $\left\{F\left(x_{n}, y_{n}\right)\right\}$ is $G$-convergent to $F(x, y)$ where $\left\{x_{n}\right\}$ and $\left\{y_{n}\right\}$ are any two $G$-convergent sequences converging to $x$ and $y$, respectively.

Definition 2.6 Let $(X, \preceq)$ be a partially ordered set, $(X, G)$ be a $G$-metric space and $g$ : $X \rightarrow X$ be a mapping. A partially ordered $G$-metric space, $(X, G, \preceq)$, is called $g$-ordered complete if for each convergent sequence $\left\{x_{n}\right\}_{n=0}^{\infty} \subset X$, the following conditions hold:

$\left(\mathrm{OC}_{1}\right)$ if $\left\{x_{n}\right\}$ is a nonincreasing sequence in $X$ such that $x_{n} \rightarrow x^{*}$, then $g x^{*} \preceq g x_{n} \forall n \in \mathbb{N}$, $\left(\mathrm{OC}_{2}\right)$ if $\left\{y_{n}\right\}$ is a nondecreasing sequence in $X$ such that $y_{n} \rightarrow y^{*}$, then $g y^{*} \succeq g y_{n} \forall n \in \mathbb{N}$.

In particular, a partially ordered $G$-metric space, $(X, G, \preceq)$, is called ordered complete when $g$ is equal to an identity mapping in $\left(\mathrm{OC}_{1}\right)$ and $\left(\mathrm{OC}_{2}\right)$.

In [48], Mustafa characterized the well-known Banach contraction principle mapping in the context of $G$-metric spaces in the following ways.

Theorem 2.1 (See [48]) Let $(X, G)$ be a complete G-metric space and $T: X \rightarrow X$ be a mapping satisfying the following condition for all $x, y, z \in X$ :

$$
G(T x, T y, T z) \leq k G(x, y, z)
$$

where $k \in[0,1)$. Then $T$ has a unique fixed point. 
Theorem 2.2 (See [48]) Let $(X, G)$ be a complete G-metric space and $T: X \rightarrow X$ be a mapping satisfying the following condition for all $x, y \in X$ :

$$
G(T x, T y, T y) \leq k G(x, y, y)
$$

where $k \in[0,1)$. Then $T$ has a unique fixed point.

Remark 2.1 The condition (2) implies the condition (3). The converse is true only if $k \in$ $\left[0, \frac{1}{2}\right)$. For details, see [48].

In 1987, Guo and Lakshmikantham [36] introduced the notion of coupled fixed point. The concept of coupled fixed point was reconsidered by Gnana-Bhaskar and Lakshmikantham [22] in 2006. In this paper, they proved the existence and uniqueness of a coupled fixed point of an operator $F: X \times X \rightarrow X$ on a partially ordered metric space under a condition called the mixed monotone property.

Definition 2.7 ([22]) Let $(X, \preceq)$ be a partially ordered set and $F: X \times X \rightarrow X$. The mapping $F$ is said to have the mixed monotone property if $F(x, y)$ is monotone nondecreasing in $x$ and monotone nonincreasing in $y$; that is, for any $x, y \in X$,

$$
x_{1}, x_{2} \in X, \quad x_{1} \preceq x_{2} \quad \Rightarrow \quad F\left(x_{1}, y\right) \preceq F\left(x_{2}, y\right)
$$

and

$$
y_{1}, y_{2} \in X, \quad y_{1} \preceq y_{2} \quad \Rightarrow \quad F\left(x, y_{1}\right) \succeq F\left(x, y_{2}\right) .
$$

Definition 2.8 ([22]) An element $(x, y) \in X \times X$ is called a coupled fixed point of the mapping $F: X \times X \rightarrow X$ if

$$
x=F(x, y) \text { and } y=F(y, x) .
$$

The results in [22] were extended by Ćirić and Lakshmikantham in [23] by defining the mixed $g$-monotone property.

Definition 2.9 Let $(X, \preceq)$ be a partially ordered set, $F: X \times X \rightarrow X$ and $g: X \rightarrow X$. The function $F$ is said to have the mixed $g$-monotone property if $F(x, y)$ is monotone $g$ nondecreasing in $x$ and is monotone $g$-nonincreasing in $y$; that is, for any $x, y \in X$,

$$
g\left(x_{1}\right) \preceq g\left(x_{2}\right) \quad \Rightarrow \quad F\left(x_{1}, y\right) \preceq F\left(x_{2}, y\right), \quad \text { for } x_{1}, x_{2} \in X,
$$

and

$$
g\left(y_{1}\right) \preceq g\left(y_{2}\right) \quad \Rightarrow \quad F\left(x, y_{2}\right) \preceq F\left(x, y_{1}\right), \quad \text { for } y_{1}, y_{2} \in X .
$$

It is clear that Definition 2.9 reduces to Definition 2.7 when $g$ is the identity. 
Definition 2.10 An element $(x, y) \in X \times X$ is called a coupled coincidence point of mappings $F: X \times X \rightarrow X$ and $g: X \rightarrow X$ if

$$
F(x, y)=g(x), \quad F(y, x)=g(y)
$$

and is called a coupled common fixed point of $F$ and $g$ if

$$
F(x, y)=g(x)=x, \quad F(y, x)=g(y)=y .
$$

The mappings $F$ and $g$ are said to commute if

$$
g(F(x, y))=F(g(x), g(y))
$$

for all $x, y \in X$.

\section{Auxiliary results}

We first state the following theorem about the existence and uniqueness of a common fixed point which can be considered as a generalization of Theorem 2.1.

Theorem 3.1 Let $(X, G)$ be a G-metric space. Let $T: X \rightarrow X$ and $g: X \rightarrow X$ be two mappings such that

$$
G(T x, T y, T z) \leq k G(g x, g y, g z)
$$

for all $x, y, z$. Assume that $T$ and $g$ satisfy the following conditions:

(A1) $T(X) \subset g(X)$,

(A2) $g(X)$ is G-complete,

(A3) $g$ is G-continuous and commutes with $T$.

If $k \in[0,1)$, then there is a unique $x \in X$ such that $g x=T x=x$.

Proof Let $x_{0} \in X$. By assumption (A1), there exists $x_{1} \in X$ such that $T x_{0}=g x_{1}$. By the same arguments, there exists $x_{2} \in X$ such that $T x_{1}=g x_{2}$. Inductively, we define a sequence $\left\{x_{n}\right\}$ in the following way:

$$
g x_{n+1}=T x_{n}, \quad n \in \mathbb{N} .
$$

Due to (6), we have

$$
\begin{aligned}
G\left(g x_{n+2}, g x_{n+2}, g x_{n+1}\right) & =G\left(T x_{n+1}, T x_{n+1}, T x_{n}\right) \\
& \leq k G\left(g x_{n+1}, g x_{n+1}, g x_{n}\right)
\end{aligned}
$$

by taking $x=y=x_{n+1}$ and $z=x_{n}$. Thus, for each natural number $n$, we have

$$
G\left(g x_{n+2}, g x_{n+2}, g x_{n+1}\right) \leq k^{n+1} G\left(g x_{1}, g x_{1}, g x_{0}\right) .
$$


We will show that $\left\{g x_{n}\right\}$ is a Cauchy sequence. By the rectangle inequality, we have for $m>n$

$$
\begin{aligned}
G\left(g x_{m}, g x_{m}, g x_{n}\right) \leq & G\left(g x_{n+1}, g x_{n+1}, g x_{n}\right)+G\left(g x_{n+2}, g x_{n+2}, g x_{n+1}\right) \\
& +\cdots+G\left(g x_{m-1}, g x_{m-1}, g x_{m-2}\right)+G\left(g x_{m}, g x_{m}, g x_{m-1}\right) \\
\leq & k^{n} G\left(g x_{1}, g x_{1}, g x_{0}\right)+k^{n+1} G\left(g x_{1}, g x_{1}, g x_{0}\right) \\
& +\cdots+k^{m-2} G\left(g x_{1}, g x_{1}, g x_{0}\right)+k^{m-1} G\left(g x_{1}, g x_{1}, g x_{0}\right) \\
\leq & \left(\sum_{i=n}^{m-1} k^{i}\right) G\left(g x_{1}, g x_{1}, g x_{0}\right) .
\end{aligned}
$$

Letting $n, m \rightarrow \infty$ in (9), we get that $G\left(g x_{m}, g x_{m}, g x_{n}\right) \rightarrow 0$. Hence, $\left\{g x_{n}\right\}$ is a $G$-Cauchy sequence in $g(X)$. Since $(g(X), G)$ is $G$-complete, then there exists $z \in X$ such that $\left\{g x_{n}\right\} \rightarrow z$. Since $g$ is $G$-continuous, we have $\left\{g g x_{n}\right\}$ is $G$-convergent to $g z$. On the other hand, we have $g g x_{n+1}=g T x_{n}=T g x_{n}$ since $g$ and $T$ commute. Thus,

$$
\begin{aligned}
G\left(g x_{n+1}, T z, T z\right) & =G\left(T g x_{n}, T z, T z\right) \\
& \leq k G\left(g g x_{n}, g z, g z\right) .
\end{aligned}
$$

Letting $n \rightarrow \infty$ and using the fact that the metric $G$ is continuous, we get that

$$
G(g z, T z, T z) \leq k G(g z, g z, g z) .
$$

Hence $g z=T z$. The sequence $\left\{g x_{n+1}\right\}$ is G-convergent to $z$ since $\left\{g x_{n+1}\right\}$ is a subsequence of $\left\{g x_{n}\right\}$. So, we have

$$
\begin{aligned}
G\left(g x_{n+1}, g z, g z\right) & =G\left(g x_{n+1}, T z, T z\right) \\
& =G\left(T x_{n}, T z, T z\right) \\
& \leq k G\left(g x_{n}, z, z\right) .
\end{aligned}
$$

Letting $n \rightarrow \infty$ and using the fact that $G$ is continuous, we obtain that

$$
G(z, g z, g z) \leq k G(z, z, z)=0 .
$$

Hence we have $z=g z=T z$. We will show that $z$ is the unique common fixed point of $T$ and $g$. Suppose that, contrary to our claim, there exists another common fixed point $w \in X$ with $w \neq z$. From (6) we have

$$
G(w, w, z)=G(T w, T w, T z) \leq k G(w, w, z)
$$

which is a contradiction since $k<1$. Hence, the common fixed point of $T$ and $g$ is unique.

Theorem 3.2 Let $(X, G)$ be a G-metric space. Let $T: X \rightarrow X$ and $g: X \rightarrow X$ be two mappings such that

$$
G(T x, T y, T y) \leq k G(g x, g y, g y)
$$


for all $x, y$. Assume that $T$ and $g$ satisfy the following conditions:

(A1) $T(X) \subset g(X)$,

(A2) $g(X)$ is G-complete,

(A3) $g$ is G-continuous and commutes with $T$.

If $k \in[0,1)$, then there is a unique $x \in X$ such that $g x=T x=x$.

Proof Following the lines of the proof of Theorem 3.1 by taking $y=z$, one can easily get the result.

In [16], Ran and Reurings established the following fixed point theorem that extends the Banach contraction principle to the setting of ordered metric spaces.

Theorem 3.3 (Ran and Reurings [16]) Let $(X, \preceq)$ be an ordered set endowed with a metric $d$ and $T: X \rightarrow X$ be a given mapping. Suppose that the following conditions hold:

(i) $(X, d)$ is complete;

(ii) $T$ is continuous and nondecreasing (with respect to $\preceq$ );

(iii) there exists $x_{0} \in X$ such that $x_{0} \preceq T x_{0}$;

(iv) there exists a constant $k \in(0,1)$ such that for all $x, y \in X$ with $x \geq y$,

$$
d(T x, T y) \leq k d(x, y) .
$$

Then $T$ has a fixed point. Moreover, if for all $(x, y) \in X \times X$ there exists $z \in X$ such that $x \preceq z$ and $y \preceq z$, we obtain uniqueness of the fixed point.

The result of Ran and Reurings [16] can be also proved in the framework of a G-metric space.

Theorem 3.4 Let $(X, \preceq)$ be an ordered set endowed with a $G$-metric and $T: X \rightarrow X$ be a given mapping. Suppose that the following conditions hold:

(i) $(X, G)$ is G-complete;

(ii) $T$ is G-continuous and nondecreasing (with respect to $\preceq$ );

(iii) there exists $x_{0} \in X$ such that $x_{0} \preceq T x_{0}$;

(iv) there exists a constant $k \in(0,1)$ such that for all $x, y, z \in X$ with $x \geq y \geq z$,

$$
G(T x, T y, T z) \leq k G(x, y, z) .
$$

Then $T$ has a fixed point. Moreover, if for all $(x, y) \in X \times X$ there exists $w \in X$ such that $x \preceq w$ and $y \preceq w$, we obtain uniqueness of the fixed point.

Proof Let $x_{0} \in X$ be a point satisfying (iii), that is, $x_{0} \preceq T x_{0}$. We define a sequence $\left\{x_{n}\right\}$ in $X$ as follows:

$$
x_{n}=T x_{n-1} \quad \text { for } n \geq 1 .
$$

Regarding that $T$ is a nondecreasing mapping together with (12), we have $x_{0} \preceq T x_{0}=x_{1}$ implies $x_{1}=T x_{0} \preceq T x_{1}=x_{2}$. Inductively, we obtain

$$
x_{0} \preceq x_{1} \preceq x_{2} \preceq \cdots \preceq x_{n-1} \preceq x_{n} \preceq x_{n+1} \preceq \cdots .
$$


Assume that there exists $n_{0}$ such that $x_{n_{0}}=x_{n_{0}+1}$. Since $x_{n_{0}}=x_{n_{0}+1}=T x_{n_{0}}$, then $x_{n_{0}}$ is the fixed point of $T$, which completes the existence part of the proof. Suppose that $x_{n} \neq x_{n+1}$ for all $n \in \mathbb{N}$. Thus, by (13) we have

$$
x_{0} \prec x_{1} \prec x_{2} \prec \cdots \prec x_{n-1} \prec x_{n} \prec x_{n+1} \prec \cdots
$$

Put $x=y=x_{n}$ and $z=x_{n-1}$ in (11). Then

$$
\begin{aligned}
0 & \leq G\left(T x_{n}, T x_{n}, T x_{n-1}\right)=G\left(x_{n+1}, x_{n+1}, x_{n}\right) \leq k G\left(x_{n}, x_{n}, x_{n-1}\right) \\
& \leq k^{2} G\left(x_{n-1}, x_{n-1}, x_{n-2}\right) \\
& \ldots \\
& \leq k^{n} G\left(x_{1}, x_{1}, x_{0}\right) .
\end{aligned}
$$

Then we have

$$
0 \leq G\left(x_{n+1}, x_{n+1}, x_{n}\right) \leq k^{n} G\left(x_{1}, x_{1}, x_{0}\right),
$$

which, upon letting $n \rightarrow \infty$, implies

$$
\lim _{n \rightarrow \infty} G\left(x_{n+1}, x_{n+1}, x_{n}\right)=0 .
$$

On the other hand, by Lemma 2.1 we have

$$
G(y, y, x) \leq G(y, x, x)+G(x, y, x)=2 G(y, x, x)
$$

The inequality (17) with $x=x_{n}$ and $y=x_{n-1}$ becomes

$$
G\left(x_{n-1}, x_{n-1}, x_{n}\right)=G\left(x_{n}, x_{n-1}, x_{n-1}\right) \leq 2 G\left(x_{n-1}, x_{n}, x_{n}\right)
$$

Letting $n \rightarrow \infty$ in (18), we get

$$
\lim _{n \rightarrow \infty} G\left(x_{n}, x_{n-1}, x_{n-1}\right)=0 .
$$

We will show that the sequence $\left\{x_{n}\right\}$ is a Cauchy sequence in the metric space $\left(X, d_{G}\right)$ where $d_{G}$ is given in (1). For $n \geq l$ we have

$$
\begin{aligned}
d_{G}\left(x_{n}, x_{l}\right) \leq & d_{G}\left(x_{n}, x_{n-1}\right)+d_{G}\left(x_{n-1}, x_{n-2}\right)+\cdots+d_{G}\left(x_{l+1}, x_{l}\right) \\
= & G\left(x_{n}, x_{n-1}, x_{n-1}\right)+G\left(x_{n-1}, x_{n}, x_{n}\right) \\
& +G\left(x_{n-1}, x_{n-2}, x_{n-2}\right)+G\left(x_{n-2}, x_{n-1}, x_{n-1}\right)+\cdots \\
& +G\left(x_{l+1}, x_{l}, x_{l}\right)+G\left(x_{l}, x_{l+1}, x_{l+1}\right) \\
= & \sum_{i=l+1}^{n}\left[G\left(x_{i}, x_{i-1}, x_{i-1}\right)+G\left(x_{i-1}, x_{i}, x_{i}\right)\right],
\end{aligned}
$$


and making use of (15) and (18), we obtain

$$
\begin{aligned}
0 & \leq d_{G}\left(x_{n}, x_{l}\right) \leq \sum_{i=l+1}^{n} 3 k^{i-1} G\left(x_{1}, x_{1}, x_{0}\right) \\
& \leq 3 G\left(x_{1}, x_{1}, x_{0}\right)\left[\sum_{i=0}^{n} k^{i-1}-\sum_{i=0}^{l} k^{i-1}\right] .
\end{aligned}
$$

Hence,

$$
d_{G}\left(x_{n}, x_{l}\right) \rightarrow 0 \quad \text { as } n, l \rightarrow \infty,
$$

that is, the sequence $\left\{x_{n}\right\}$ is Cauchy in $\left(X, d_{G}\right)$ and hence $\left\{x_{n}\right\}$ is G-Cauchy in $(X, G)$ (see Proposition 9 in [7]). Since the space $(X, G)$ is $G$-complete, then $\left(X, d_{G}\right)$ is complete (see Proposition 10 in [7]). Thus, $\left\{x_{n}\right\}$ is $G$-convergent to a number, say $u \in X$, that is,

$$
\lim _{n \rightarrow \infty} G\left(x_{n}, x_{n}, u\right)=\lim _{n \rightarrow \infty} G\left(x_{n}, u, u\right)=0 .
$$

We show now that $u \in X$ is a fixed point of $T$, that is, $u=T u$. By the $G$-continuity of $T$, the sequence $\left\{T x_{n}\right\}=\left\{x_{n+1}\right\}$ converges to $T u$, that is,

$$
\lim _{n \rightarrow \infty} G\left(T x_{n}, T x_{n}, T u\right)=\lim _{n \rightarrow \infty} G\left(T x_{n}, T u, T u\right)=0 .
$$

The rectangle inequality on the other hand gives

$$
\begin{aligned}
G(u, T u, T u) & \leq G\left(u, x_{n+1}, x_{n+1}\right)+G\left(x_{n+1}, T u, T u\right) \\
& \leq G\left(u, x_{n+1}, x_{n+1}\right)+G\left(T x_{n}, T u, T u\right) .
\end{aligned}
$$

Passing to limit as $n \rightarrow \infty$ in (25), we conclude that $G(u, T u, T u)=0$. Hence, $u=T u$, that is, $u \in$ is a fixed point of $T$.

To prove the uniqueness, we assume that $v \in X$ is another fixed point of $T$ such that $v \neq u$. We examine two cases. For the first case, assume that either $v \preceq u$ or $u \preceq v$. Then we substitute $x=u$ and $y=z=v$ in (11) which yields $G(T v, T u, T u) \leq k G(u, v, v)$. This is true only for $k=1$, but $k \in(0,1)$ by definition. Thus, the fixed point of $T$ is unique.

For the second case, we suppose that neither $v \preceq u$ nor $u \preceq v$ holds. Then by assumption (iv), there exists $w \in X$ such that $u \preceq w$ and $v \preceq w$. Substituting $x=y=w$ and $z=u$ in (11), we get that $G(T w, T w, T u)=G(T w, T w, u) \leq k G(w, w, u)$. Since $T$ is nondecreasing, $T u \preceq T w$. Substitute now $x=y=T w$ and $z=T u$, which implies $G\left(T^{2} w, T^{2} w, T^{2} u\right) \leq$ $k G(T w, T w, T u) \leq k^{2} G(w, w, u)$. Continuing in this way, we conclude $G\left(T^{n} w, T^{n} w, u\right) \leq$ $k^{n} G(w, w, u)$. Passing to limit as $n \rightarrow \infty$, we get

$$
\lim _{n \rightarrow \infty} G\left(T^{n} w, T^{n} w, u\right)=0
$$

Similarly, if we take $x=y=w$ and $z=v$ in (11), then we obtain

$$
\lim _{n \rightarrow \infty} G\left(T^{n} w, T^{n} w, v\right)=0 .
$$


From (26) and (27), we deduce $\left\{T^{n} w\right\} \rightarrow u$ and $\left\{T^{n} w\right\} \rightarrow v$. The uniqueness of the limit implies that $u=v$. Hence, the fixed point of $T$ is unique.

Corollary 3.1 Let $(X, \preceq)$ be an ordered set endowed with a G-metric and $T: X \rightarrow X$ be a given mapping. Suppose that the following conditions hold:

(i) $(X, G)$ is G-complete;

(ii) $T$ is G-continuous and nondecreasing (with respect to $\preceq$ );

(iii) there exists $x_{0} \in X$ such that $x_{0} \preceq T x_{0}$;

(iv) there exists a constant $k \in(0,1)$ such that for all $x, y \in X$ with $x \geq y$,

$$
G(T x, T y, T y) \leq k G(x, y, y)
$$

Then $T$ has a fixed point. Moreover, if for all $(x, y) \in X \times X$ there exists $w \in X$ such that $x \preceq w$ and $y \preceq w$, we obtain uniqueness of the fixed point.

Proof It is sufficient to take $z=y$ in the proof of Theorem 3.4.

Nieto and López [49] extended the result of Ran and Reurings [16] for a mapping $T$ not necessarily continuous by assuming an additional hypothesis on $(X, \preceq, d)$.

Theorem 3.5 (Nieto and López [49]) Let $(X, \preceq)$ be an ordered set endowed with a metric $d$ and $T: X \rightarrow X$ be a given mapping. Suppose that the following conditions hold:

(i) $(X, d)$ is complete;

(ii) $X$ is ordered complete;

(iii) $T$ is nondecreasing;

(iv) there exists $x_{0} \in X$ such that $x_{0} \preceq T x_{0}$;

(v) there exists a constant $k \in(0,1)$ such that for all $x, y \in X$ with $x \geq y$,

$$
d(T x, T y) \leq k d(x, y) .
$$

Then $T$ has a fixed point. Moreover, if for all $(x, y) \in X \times X$ there exists $w \in X$ such that $x \preceq w$ and $y \preceq w$, we obtain uniqueness of the fixed point.

The result of Nieto and López [49] can also be proved in the framework of G-metric space.

Theorem 3.6 Let $(X, \preceq)$ be an ordered set endowed with a G-metric and $T: X \rightarrow X$ be a given mapping. Suppose that the following conditions hold:

(i) $(X, G)$ is G-complete;

(ii) $X$ is ordered complete;

(iii) $T$ is nondecreasing;

(iv) there exists $x_{0} \in X$ such that $x_{0} \preceq T x_{0}$;

(v) there exists a constant $k \in(0,1)$ such that for all $x, y, z \in X$ with $x \succeq y \geq z$,

$$
G(T x, T y, T z) \leq k G(x, y, z)
$$

Then $T$ has a fixed point. Moreover, if for all $(x, y) \in X \times X$ there exists $w \in X$ such that $x \preceq w$ and $y \preceq w$, we obtain uniqueness of the fixed point. 
Proof Following the lines in the proof of Theorem 3.4, we have a sequence $\left\{x_{n}\right\}$ which is $G$-convergent to $u \in X$. Due to (ii), we have $x_{n} \preceq u$ for all $n$. We will show that $u$ is a fixed point of $T$. Suppose on the contrary that $u \neq T u$, that is, $d_{G}(u, T u)>0$. Regarding (1) and (29) with $x=x_{n}, y=z=T u$, we have

$$
\begin{aligned}
0 & \leq d_{G}\left(x_{n}, T u\right)=G\left(x_{n}, T u, T u\right)+G\left(T u, x_{n}, x_{n}\right) \\
& =G\left(T x_{n-1}, T u, T u\right)+G\left(T u, T x_{n-1}, T x_{n-1}\right) \\
& \leq k\left[G\left(x_{n-1}, u, u\right)+G\left(u, x_{n-1}, x_{n-1}\right)\right] .
\end{aligned}
$$

Passing to limit as $n \rightarrow \infty$, we get $d_{G}(u, T u)=0$, which is a contradiction. Hence, $T u=u$. Uniqueness of $u$ can be observed as in the proof of Theorem 3.4.

Corollary 3.2 Let $(X, \preceq)$ be an ordered set endowed with a G-metric and $T: X \rightarrow X$ be a given mapping. Suppose that the following conditions hold:

(i) $(X, G)$ is G-complete;

(ii) $X$ is ordered complete;

(iii) $T$ is nondecreasing;

(iv) there exists $x_{0} \in X$ such that $x_{0} \preceq T x_{0}$;

(v) there exists a constant $k \in(0,1)$ such that for all $x, y \in X$ with $x \geq y$,

$$
G(T x, T y, T y) \leq k G(x, y, y) .
$$

Then $T$ has a fixed point. Moreover, if for all $(x, y) \in X \times X$ there exists $w \in X$ such that $x \preceq w$ and $y \preceq w$, we obtain uniqueness of the fixed point.

Proof It is sufficient to take $z=y$ in the proof of Theorem 3.6.

Denote by $\Psi$ the set of functions $\psi:[0, \infty) \rightarrow[0, \infty)$ satisfying the following conditions:

$\left(\Psi_{0}\right) \psi^{-1}(\{0\})=0$,

$\left(\Psi_{1}\right) \psi(t)<t$ for all $t>0$;

$\left(\Psi_{2}\right) \lim _{r \rightarrow t^{+}} \psi(r)<t$

Following the work of Ćirić et al. [50], we generalize the above-mentioned results by means of introducing a function $g$. More specifically, we modify the definitions and theorems according to the presence of the function $g$.

Definition 3.1 (See [50]) Let $(X, \preceq)$ be an ordered set and $T: X \rightarrow X$ and $g: X \rightarrow X$ be given mappings. The mapping $T$ is called $g$-nondecreasing if for every $x, y \in X$,

$$
g x \preceq g y \text { implies } T x \preceq T y .
$$

Theorem 3.7 Let $(X, \preceq)$ be an ordered set endowed with a G-metric and $T: X \rightarrow X$ and $g: X \rightarrow X$ be given mappings. Suppose that the following conditions hold:

(i) $(X, G)$ is G-complete;

(ii) $T$ is G-continuous; 
(iii) $T$ is g-nondecreasing;

(iv) there exists $x_{0} \in X$ such that $g x_{0} \preceq T x_{0}$;

(v) $T(X) \subset g(X)$ and $g$ is $G$-continuous and commutes with $T$;

(vi) there exists a function $\varphi \in \Psi$ such that for all $x, y, z \in X$ with $g x \succeq g y \succeq g z$,

$$
G(T x, T y, T z) \leq \varphi(G(g x, g y, g z))
$$

Then $T$ and $g$ have a coincidence point, that is, there exists $w \in X$ such that $g w=T w$.

Proof Let $x_{0} \in X$ such that $g x_{0} \preceq T x_{0}$. Since $T(X) \subset g(X)$, we can choose $x_{1}$ such that $g x_{1}=T x_{0}$. Again, by $T(X) \subset g(X)$, we can choose $x_{2}$ such that $g x_{2}=T x_{1}$. By repeating the same argument, we construct the sequence $\left\{g x_{n}\right\}$ in the following way:

$$
g x_{n+1}=T x_{n}, \quad \text { for all } n=0,1,2, \ldots
$$

Regarding that $T$ is a $g$-nondecreasing mapping together with (33), we observe that

$$
g x_{0} \preceq T x_{0}=g x_{1} \quad \text { implies } g x_{1}=T x_{0} \preceq T x_{1}=g x_{2} .
$$

Inductively, we obtain

$$
g x_{0} \preceq g x_{1} \preceq g x_{2} \preceq \cdots \preceq g x_{n-1} \preceq g x_{n} \preceq g x_{n+1} \preceq \cdots .
$$

If there exists $n_{0}$ such that $g x_{n_{0}}=g x_{n_{0}+1}$, then $g x_{n_{0}}=g x_{n_{0}+1}=T x_{n_{0}}$, that is, $T$ and $g$ have a coincidence point which completes the proof. Assume that $g x_{n} \neq g x_{n+1}$ for all $n \in \mathbb{N}$.

Regarding (34), we set $x=y=x_{n+1}$ and $z=x_{n}$ in (32). Then we get

$$
G\left(T x_{n+1}, T x_{n+1}, T x_{n}\right) \leq \varphi\left(G\left(g x_{n+1}, g x_{n+1}, g x_{n}\right)\right)
$$

which is equivalent to

$$
G\left(g x_{n+2}, g x_{n+2}, g x_{n+1}\right) \leq \varphi\left(G\left(g x_{n+1}, g x_{n+1}, g x_{n}\right)\right)<G\left(g x_{n+1}, g x_{n+1}, g x_{n}\right)
$$

since $\varphi(t)<t$ for all $t>0$. Let $t_{n}=G\left(g x_{n+1}, g x_{n+1}, g x_{n}\right)$. Then $\left\{t_{n}\right\}$ is a positive nonincreasing sequence. Thus, there exists $L \geq 0$ such that

$$
\lim _{n \rightarrow \infty} t_{n}=L^{+}
$$

We will show that $L=0$. Suppose that contrary to our claim, $L>0$. Letting $n \rightarrow \infty$ in (35), we get

$$
L=\lim _{n \rightarrow \infty} t_{n+1} \leq \lim _{n \rightarrow \infty} \varphi\left(t_{n}\right)=\lim _{t \rightarrow L^{+}} \varphi(t)<L,
$$

which is a contradiction. Hence, we have

$$
\lim _{n \rightarrow \infty} G\left(g x_{n+1}, g x_{n+1}, g x_{n}\right)=\lim _{n \rightarrow \infty} t_{n}=0 .
$$


We will show that $\left\{g x_{n}\right\}$ is a G-Cauchy sequence. Suppose on the contrary that the sequence $\left\{g x_{n}\right\}$ is not G-Cauchy. Then there exists $\varepsilon>0$ and sequences of natural numbers $\{m(k)\},\{l(k)\}$ such that for each natural number $k$,

$$
m(k)>l(k) \geq k,
$$

and we have

$$
c_{k}=G\left(g x_{m(k)}, g x_{m(k)}, g x_{l(k)}\right) \geq \varepsilon .
$$

Corresponding to $l(k)$, the number $m(k)$ is chosen to be the smallest number for which (38) holds. Hence, we have

$$
G\left(g x_{m(k)-1}, g x_{m(k)-1}, g x_{l(k)}\right)<\varepsilon .
$$

By using (G5), we obtain that

$$
\begin{aligned}
\varepsilon & \leq G\left(g x_{m(k)}, g x_{m(k)}, g x_{l(k)}\right) \\
& \leq G\left(g x_{m(k)}, g x_{m(k)}, g x_{m(k)-1}\right)+G\left(g x_{m(k)-1}, g x_{m(k)-1}, g x_{l(k)}\right) \\
& =t_{m(k)-1}+G\left(g x_{m(k)-1}, g x_{m(k)-1}, g x_{l(k)}\right) \\
& <t_{m(k)-1}+\varepsilon .
\end{aligned}
$$

Regarding (37) and letting $n \rightarrow \infty$ in the previous inequality, we deduce

$$
\lim _{k \rightarrow \infty} c_{k}=\varepsilon^{+}
$$

Again by the rectangle inequality (G5), together with (G4) and Lemma 2.1, we get that

$$
\begin{aligned}
c_{k} & =G\left(g x_{m(k)}, g x_{m(k)}, g x_{l(k)}\right) \\
& \leq G\left(g x_{m(k)}, g x_{m(k)}, g x_{m(k)+1}\right)+G\left(g x_{m(k)+1}, g x_{m(k)+1}, g x_{l(k)+1}\right)+G\left(g x_{l(k)+1}, g x_{l(k)+1}, g x_{l(k)}\right) \\
& =t_{l(k)}+G\left(g x_{m(k)}, g x_{m(k)}, g x_{m(k)+1}\right)+G\left(g x_{m(k)+1}, g x_{m(k)+1}, g x_{l(k)+1}\right) \\
& \leq t_{l(k)}+2 G\left(g x_{m(k+1)}, g x_{m(k)+1}, g x_{m(k)}\right)+G\left(g x_{m(k)+1}, g x_{m(k)+1}, g x_{l(k)+1}\right) \\
& \leq t_{l(k)}+2 t_{m(k)}+G\left(g x_{m(k)+1}, g x_{m(k)+1}, g x_{l(k)+1}\right) .
\end{aligned}
$$

Setting $x=y=x_{m(k)}$ and $z=x_{l(k)}$, the inequality (32) implies

$$
\begin{aligned}
G\left(g x_{m(k)+1}, g x_{m(k)+1}, g x_{l(k)+1}\right) & =G\left(T x_{m(k)}, T x_{m(k)}, T x_{l(k)}\right) \\
& \leq \varphi\left(G\left(g x_{m(k)}, g x_{m(k)}, g x_{l(k)}\right)\right) \\
& =\varphi\left(c_{k}\right) .
\end{aligned}
$$

Combining the inequalities (41) and (42), we find

$$
c_{k} \leq t_{l(k)}+2 t_{m(k)}+\varphi\left(c_{k}\right) .
$$


Taking (37) and (40) into account and letting $k \rightarrow \infty$ in (43), we obtain that

$$
\varepsilon \leq \lim _{k \rightarrow \infty} \varphi\left(c_{k}\right)=\lim _{t \rightarrow \varepsilon^{+}} \varphi(t)<\varepsilon
$$

which is a contradiction. Hence, $\left\{g x_{n}\right\}$ is a G-Cauchy sequence in the G-metric space $(X, G)$. Since $(X, G)$ is $G$-complete, there exists $w \in X$ such that $\left\{g x_{n}\right\}$ is $G$-convergent to $w$. By Proposition 2.1, we have

$$
\lim _{n \rightarrow \infty} G\left(g x_{n}, g x_{n}, w\right)=\lim _{n \rightarrow \infty} G\left(g x_{n}, w, w\right)=0 .
$$

The G-continuity of $g$ implies that the sequence $\left\{g g x_{n}\right\}$ is G-convergent to $g w$, that is,

$$
\lim _{n \rightarrow \infty} G\left(g g x_{n}, g g x_{n}, g w\right)=\lim _{n \rightarrow \infty} G\left(g g x_{n}, g w, g w\right)=0 .
$$

On the other hand, due to the commutativity of $T$ and $g$, we can write

$$
g g x_{n+1}=g T x_{n}=\operatorname{Tg} x_{n}
$$

and the $G$-continuity of $T$ implies that the sequence $\left\{\operatorname{Tg} x_{n}\right\}=\left\{g g x_{n+1}\right\} G$-converges to $T w$ so that

$$
\lim _{n \rightarrow \infty} G\left(\operatorname{Tg} x_{n}, \operatorname{Tg} x_{n}, T w\right)=\lim _{n \rightarrow \infty} G\left(\operatorname{Tg} x_{n}, T w, T w\right)=0 .
$$

By the uniqueness of the limit, the expressions (45) and (47) yield that $g w=T w$. Indeed, from the rectangle inequality, we get

$$
\begin{aligned}
G(g w, T w, T w) & \leq G\left(g z, g g x_{n+1}, g g x_{n+1}\right)+G\left(g g x_{n+1}, T w, T w\right) \\
& \leq G\left(g w, g g x_{n+1}, g g x_{n+1}\right)+G\left(T g x_{n}, T w, T w\right),
\end{aligned}
$$

which implies $G(g w, T w, T w)=0$ upon letting $n \rightarrow \infty$. Hence, $g w=T w$.

In the next theorem, $G$-continuity of $T$ is no longer required. However, we require the $g$-ordered completeness of $X$.

Theorem 3.8 Let $(X, \preceq)$ be an ordered set endowed with a $G$-metric and $T: X \rightarrow X$ and $g: X \rightarrow X$ be given mappings. Suppose that the following conditions hold:

(i) $(X, G)$ is G-complete;

(ii) $X$ is g-ordered complete;

(iii) $T$ is $g$-nondecreasing (with respect to $\preceq$ );

(iv) there exists $x_{0} \in X$ such that $g x_{0} \preceq T x_{0}$;

(v) $T(X) \subset g(X)$ and $g$ is $G$-continuous and commutes with $T$;

(vi) there exists a function $\varphi \in \Psi$ such that for all $x, y, z \in X$ with $g x \succeq g y \succeq g z$,

$$
G(T x, T y, T z) \leq \varphi(G(g x, g y, g z)) .
$$

Then $T$ and $g$ have a coincidence point, that is, there exists $w \in X$ such that $g w=T w$. 
Proof Following the lines of the proof of Theorem 3.7, we define a sequence $\left\{g x_{n}\right\}$ and conclude that it is a $G$-Cauchy sequence in the $G$-complete, $G$-metric space $(X, G)$. Thus, there exists $w \in X$ such that $g x_{n}$ is $G$-convergent to $g w$. Since $\left\{g x_{n}\right\}$ is nondecreasing and $X$ is $g$-ordered complete, we have $g x_{n} \preceq g w$. If $g w=g x_{n}$ for some natural number $n$, then $T$ and $g$ have a coincidence point. Indeed, $g w=g x_{n} \preceq g x_{n+1}=T x_{n} \preceq g w$ and hence $g x_{n}=T x_{n}$. Suppose that $g w \neq g x_{n}$. By the rectangle inequality together with the inequality (49) and the property $\left(\Psi_{1}\right)$, we have

$$
\begin{aligned}
G(T w, g w, g w) & \leq G\left(T w, g x_{n+1}, g x_{n+1}\right)+G\left(g x_{n+1}, g w, g w\right) \\
& \leq G\left(T w, T x_{n}, T x_{n}\right)+G\left(g x_{n+1}, g w, g w\right) \\
& \leq \varphi\left(G\left(g w, g x_{n}, g x_{n}\right)\right)+G\left(g x_{n+1}, g w, g w\right) \\
& <G\left(g w, g x_{n}, g x_{n}\right)+G\left(g x_{n+1}, g w, g w\right) .
\end{aligned}
$$

Letting $n \rightarrow \infty$ in the inequality above, we get that $G(T w, g w, g w)=0$. Hence, $T w=g w$.

If we take $\varphi(t)=k t$, where $k \in[0,1)$ in Theorem 3.7 and Theorem 3.8, we deduce the following corollaries, respectively.

Corollary 3.3 Let $(X, \preceq)$ be an ordered set endowed with a G-metric and $T: X \rightarrow X$ and $g: X \rightarrow X$ be given mappings. Suppose that the following conditions hold:

(i) $(X, G)$ is G-complete;

(ii) $T$ is G-continuous;

(iii) $T$ is $g$-nondecreasing (with respect to $\preceq$ );

(iv) there exists $x_{0} \in X$ such that $g x_{0} \preceq T x_{0}$;

(v) $T(X) \subset g(X)$ and $g$ is G-continuous and commutes with $T$;

(vi) there exists $k \in[0,1)$ such that for all $x, y, z \in X$ with $g x \geq g y \succeq g z$,

$$
G(T x, T y, T z) \leq k G(g x, g y, g z) .
$$

Then $T$ and $g$ have a coincidence point, that is, there exists $w \in X$ such that $g w=T w$.

Corollary 3.4 Let $(X, \preceq)$ be an ordered set endowed with a G-metric and $T: X \rightarrow X$ and $g: X \rightarrow X$ be given mappings. Suppose that the following conditions hold:

(i) $(X, G)$ is G-complete;

(ii) $X$ is $g$-ordered complete;

(iii) $T$ is $g$-nondecreasing (with respect to $\preceq$ );

(iv) there exists $x_{0} \in X$ such that $g x_{0} \preceq T x_{0}$;

(v) $T(X) \subset g(X)$ and $g$ is G-continuous and commutes with $T$;

(vi) there exists $k \in[0,1)$ such that for all $x, y, z \in X$ with $g x \geq g y \succeq g z$,

$$
G(T x, T y, T z) \leq k G(g x, g y, g z) .
$$

Then $T$ and $g$ have a coincidence point, that is, there exists $w \in X$ such that $g w=T w$.

If we take $z=y$ in Theorem 3.7 and Theorem 3.8, we obtain the following particular cases. 
Corollary 3.5 Let $(X, \preceq)$ be an ordered set endowed with a G-metric and $T: X \rightarrow X$ and $g: X \rightarrow X$ be given mappings. Suppose that the following conditions hold:

(i) $(X, G)$ is G-complete;

(ii) $T$ is G-continuous;

(iii) $T$ is $g$-nondecreasing;

(iv) there exists $x_{0} \in X$ such that $g x_{0} \preceq T x_{0}$;

(v) $T(X) \subset g(X)$ and $g$ is G-continuous and commutes with $T$;

(vi) there exists a function $\varphi \in \Psi$ such that for all $x, y \in X$ with $g x \geq g y$,

$$
G(T x, T y, T y) \leq \varphi(G(g x, g y, g y)) .
$$

Then $T$ and $g$ have a coincidence point, that is, there exists $w \in X$ such that $g w=T w$.

Corollary 3.6 Let $(X, \preceq)$ be an ordered set endowed with a G-metric and $T: X \rightarrow X$ and $g: X \rightarrow X$ be given mappings. Suppose that the following conditions hold:

(i) $(X, G)$ is G-complete;

(ii) $X$ is $g$-ordered complete;

(iii) $T$ is $g$-nondecreasing;

(iv) there exists $x_{0} \in X$ such that $g x_{0} \preceq T x_{0}$;

(v) $T(X) \subset g(X)$ and $g$ is G-continuous and commutes with $T$;

(vi) there exists a function $\varphi \in \Psi$ such that for all $x, y \in X$ with $g x \geq g y$,

$$
G(T x, T y, T y) \leq \varphi(G(g x, g y, g y)) .
$$

Then $T$ and $g$ have a coincidence point, that is, there exists $w \in X$ such that $g w=T w$.

Finally, we let $g=i d_{X}$ in the Theorem 3.7 and Theorem 3.8 and conclude the following theorems.

Theorem 3.9 Let $(X, \preceq)$ be an ordered set endowed with a $G$-metric and $T: X \rightarrow X$ be a given mapping. Suppose that the following conditions hold:

(i) $(X, G)$ is G-complete;

(ii) $T$ is G-continuous;

(iii) $T$ is nondecreasing (with respect to $\preceq$ );

(iv) there exists $x_{0} \in X$ such that $x_{0} \preceq T x_{0}$;

(v) there exists a function $\varphi \in \Psi$ such that for all $x, y, z \in X$ with $x \geq y \geq z$,

$$
G(T x, T y, T z) \leq \varphi(G(x, y, z))
$$

Then $T$ has a fixed point.

Theorem 3.10 Let $(X, \preceq)$ be an ordered set endowed with a G-metric and $T: X \rightarrow X$ bea given mapping. Suppose that the following conditions hold:

(i) $(X, G)$ is G-complete;

(ii) $X$ is ordered complete;

(iii) $T$ is nondecreasing;

(iv) there exists $x_{0} \in X$ such that $x_{0} \preceq T x_{0}$; 
(v) there exists a function $\varphi \in \Psi$ such that for all $x, y, z \in X$ with $x \geq y \geq z$,

$$
G(T x, T y, T z) \leq \varphi(G(x, y, z))
$$

Then $T$ has a fixed point.

We next consider some equivalence conditions and their implementation on $G$-metric spaces. Let $\mathcal{S}$ denote the set of functions $\beta:[0, \infty) \rightarrow[0,1)$ satisfying the condition

$$
\beta\left(t_{n}\right) \longrightarrow 1 \quad \text { implies } \quad t_{n} \longrightarrow 0
$$

In 2007, Jachymski and Jóźwik [51] proved that the classes $\mathcal{S}$ and $\Psi$ are equivalent. Regarding this result, we state the following fixed point theorems on $G$-metric spaces.

Theorem 3.11 Let $(X, \preceq)$ be an ordered set endowed with a G-metric and $T: X \rightarrow X$ be a given mapping. Suppose that the following conditions hold:

(i) $(X, G)$ is G-complete;

(ii) $T$ is G-continuous;

(iii) $T$ is nondecreasing (with respect to $\preceq$ );

(iv) there exists $x_{0} \in X$ such that $x_{0} \preceq T x_{0}$;

(v) there exists a function $\beta \in \mathcal{S}$ such that for all $x, y, z \in X$ with $x \succeq y \succeq z$,

$$
G(T x, T y, T z) \leq \beta(G(x, y, z)) G(x, y, z) .
$$

Then T has a fixed point.

Theorem 3.12 Let $(X, \preceq)$ be an ordered set endowed with a G-metric and $T: X \rightarrow X$ be a given mapping. Suppose that the following conditions hold:

(i) $(X, G)$ is G-complete;

(ii) $X$ is ordered complete;

(iii) $T$ is nondecreasing (with respect to $\preceq$ );

(iv) there exists $x_{0} \in X$ such that $x_{0} \preceq T x_{0}$;

(v) there exists a function $\beta \in \mathcal{S}$ such that for all $x, y, z \in X$ with $x \succeq y \geq z$,

$$
G(T x, T y, T z) \leq \beta(G(x, y, z)) G(x, y, z) .
$$

Then T has a fixed point.

The two corollaries below are immediate consequences of Theorem 3.11 and Theorem 3.12 .

Corollary 3.7 Let $(X, \preceq)$ be an ordered set endowed with a G-metric and $T: X \rightarrow X$ be a given mapping. Suppose that the following conditions hold:

(i) $(X, G)$ is G-complete;

(ii) $T$ is G-continuous;

(iii) $T$ is nondecreasing (with respect to $\preceq$ );

(iv) there exists $x_{0} \in X$ such that $x_{0} \preceq T x_{0}$; 
(v) there exists a function $\beta \in \mathcal{S}$ such that for all $x, y \in X$ with $x \geq y$,

$$
G(T x, T y, T y) \leq \beta(G(x, y, y)) G(x, y, y) .
$$

Then T has a fixed point.

Corollary 3.8 Let $(X, \preceq)$ be an ordered set endowed with a G-metric and $T: X \rightarrow X$ be a given mapping. Suppose that the following conditions hold:

(i) $(X, G)$ is G-complete;

(ii) $X$ is ordered complete;

(iii) $T$ is nondecreasing (with respect to $\preceq$ );

(iv) there exists $x_{0} \in X$ such that $x_{0} \preceq T x_{0}$;

(v) there exists a function $\beta \in \mathcal{S}$ such that for all $x, y \in X$ with $x \geq y$,

$$
G(T x, T y, T y) \leq \beta(G(x, y, y)) G(x, y, y) .
$$

Then Thas a fixed point.

Denote by $\Phi$ the set of functions $\varphi:[0, \infty) \rightarrow[0, \infty)$ satisfying the conditions $\left(\Psi_{1}\right)$ and $\left(\Psi_{2}\right)$. Jachymski [52] proved the equivalence of the so-called distance functions (see Lemma 1 in [52]). Inspired by this result, we can state the following theorem.

Theorem 3.13 Let $(X, \preceq)$ be an ordered set endowed with a G-metric and $T$ be a selfmap on a G-complete partially ordered G-metric space $(X, G)$. The following statements are equivalent:

(i) there exist functions $\psi, \eta \in \Phi$ such that

$$
\psi(G(T x, T y, T z)) \leq \psi(G(x, y, z))-\eta(G(x, y, z)),
$$

(ii) there exist $\alpha \in[0,1)$ and a function $\psi \in \Phi$ such that

$$
\psi(G(T x, T y, T z)) \leq \alpha \psi(G(x, y, z))
$$

(iii) there exists a continuous and nondecreasing function $\alpha:[0, \infty) \rightarrow[0, \infty)$ such that $\alpha(t)<t$ for all $t>0$ such that

$$
G(T x, T y, T z) \leq \alpha(G(x, y, z))
$$

(iv) there exist a function $\psi \in \Phi$ and a nondecreasing function $\eta:[0, \infty) \rightarrow[0, \infty)$ with $\eta^{-1}(0)=0$ such that

$$
\psi(G(T x, T y, T z)) \leq \psi(G(x, y, z))-\eta(G(x, y, z)),
$$

(iv) there exist a function $\psi \in \Phi$ and a lower semi-continuous function $\eta:[0, \infty) \rightarrow[0, \infty)$ with $\eta^{-1}(0)=0$ and $\liminf _{t \rightarrow \infty} \eta(t)>0$ such that

$$
\psi(G(T x, T y, T z)) \leq \psi(G(x, y, z))-\eta(G(x, y, z))
$$

for any $x, y, z \in X$ with $x \geq y \geq z$. 
As a consequence of Theorem 3.13, we state the next corollary.

Corollary 3.9 Let $(X, \preceq)$ be an ordered set endowed with a G-metric and $T$ be a self-map on a G-complete partially ordered G-metric space $(X, G)$. The following statements are equivalent:

(i) there exist functions $\psi, \eta \in \Phi$ such that

$$
\psi(G(T x, T y, T y)) \leq \psi(G(x, y, y))-\eta(G(x, y, y))
$$

(ii) there exist $\alpha \in[0,1)$ and a function $\psi \in \Phi$ such that

$$
\psi(G(T x, T y, T y)) \leq \alpha \psi(G(x, y, y))
$$

(iii) there exists a continuous and nondecreasing function $\alpha:[0, \infty) \rightarrow[0, \infty)$ such that $\alpha(t)<t$ for all $t>0$ such that

$$
G(T x, T y, T y) \leq \alpha(G(x, y, y))
$$

(iv) there exist a function $\psi \in \Phi$ and a nondecreasing function $\eta:[0, \infty) \rightarrow[0, \infty)$ with $\eta^{-1}(0)=0$ such that

$$
\psi(G(T x, T y, T y)) \leq \psi(G(x, y, y))-\eta(G(x, y, y))
$$

(iv) there exist a function $\psi \in \Phi$ and a lower semi-continuous function $\eta:[0, \infty) \rightarrow[0, \infty)$ with $\eta^{-1}(0)=0$ and $\liminf _{t \rightarrow \infty} \eta(t)>0$ such that

$$
\psi(G(T x, T y, T y)) \leq \psi(G(x, y, y))-\eta(G(x, y, y))
$$

for any $x, y \in X$ with $x \preceq y$.

\section{Remarks on coupled fixed point theorems in G-metric spaces}

In this section, we prove that most of the coupled fixed point theorems on a $G$-metric space $X$ can be derived from the well-known fixed point theorems on $G$-metric spaces in the literature provided that $(X, G)$ is a symmetric $G$-metric space. In the rest this paper, we shall assume that $(X, G)$ represents a symmetric $G$-metric space.

Let $(X, \preceq)$ be a partially ordered set endowed with a metric $G$ and $F: X \times X \rightarrow X$ and $g: X \rightarrow X$ be given mappings. We define a partial order $\preceq_{2}$ on the product set $X \times X$ as follows:

$$
(x, y),(u, v) \in X \times X, \quad(x, y) \preceq_{2}(u, v) \quad \Longleftrightarrow \quad x \preceq u, \quad y \succeq v .
$$

Definition 4.1 $F$ is said to have the mixed $g$-monotone property if $F(x, y)$ is monotone nondecreasing in $x$ and is monotone nonincreasing in $y$; that is, for any $x, y \in X$,

$$
\begin{array}{ll}
x_{1}, x_{2} \in X, \quad g x_{1} \preceq g x_{2} & \Longrightarrow \quad F\left(x_{1}, y\right) \preceq F\left(x_{2}, y\right) ; \\
y_{1}, y_{2} \in X, \quad g y_{1} \succeq g y_{2} \quad \Longrightarrow \quad F\left(x, y_{1}\right) \preceq F\left(x, y_{2}\right) .
\end{array}
$$


If $g$ is an identity mapping, then $F$ is said to have the mixed monotone property, that is,

$$
\begin{aligned}
& x_{1}, x_{2} \in X, \quad x_{1} \preceq x_{2} \quad \Longrightarrow \quad F\left(x_{1}, y\right) \preceq F\left(x_{2}, y\right) ; \\
& y_{1}, y_{2} \in X, \quad y_{1} \succeq y_{2} \quad \Longrightarrow \quad F\left(x, y_{1}\right) \preceq F\left(x, y_{2}\right) .
\end{aligned}
$$

Let $Y=X \times X$. It is easy to show that the mappings $\Lambda, \Delta: Y \times Y \times Y \rightarrow[0, \infty)$ defined by

$$
\begin{aligned}
& \Lambda((x, y),(u, v),(z, w))=G(x, u, z)+G(y, v, w) \\
& \Delta((x, y),(u, v),(z, w))=\max \{G(x, u, z), G(y, v, w)\}
\end{aligned}
$$

for all $(x, y),(u, v),(z, w) \in Y$, are $G$-metrics on $Y$.

Now, define the mapping $T: Y \rightarrow Y$ by

$$
T(x, y)=(F(x, y), F(y, x)), \quad \text { for all }(x, y) \in Y \text {. }
$$

The following lemma is obvious.

Lemma 4.1 The following properties hold:

(a) If $(X, G)$ is $G$-complete, then $(Y, \Lambda)$ and $(Y, \Delta)$ are $\Lambda$-complete and $\Delta$-complete, respectively;

(b) F has the mixed ( $g$-mixed) monotone property if and only if $T$ is monotone nondecreasing ( $g$-nondecreasing) with respect to $\preceq_{2}$;

(c) $(x, y) \in X \times X$ is a coupled fixed point of $F$ if and only if $(x, y)$ is a fixed point of $T$;

(d) $(x, y) \in X \times X$ is a coupled coincidence point of $F$ and $g$ if and only if $(x, y)$ is a coupled coincidence point of $T$ and $g$.

\subsection{Shatanawi's coupled fixed point results in a $G$-metric space}

In [31], Shatanawi proved the following theorems.

Theorem 4.1 (cf. [31]) Let $(X, G)$ be a G-complete G-metric space. Let $F: X \times X \rightarrow X$ be a mapping such that

$$
G(F(x, y), F(u, v), F(w, z)) \leq \frac{k}{2}(G(x, u, w)+G(y, v, z))
$$

for all $x, y, u, v, z, w \in X$. If $k \in[0,1)$, then there exists a unique $x \in X$ such that $F(x, x)=x$.

In what follows, we prove the following theorem.

Theorem 4.2 Theorem 4.1 follows from Theorem 2.1.

Proof From (73), for all $(x, y),(u, v),(z, w) \in Y$ with $x \succeq u \succeq z$ and $y \preceq v \preceq w$, we have

$$
G(F(x, y), F(u, v), F(z, w)) \leq \frac{k}{2}[G(x, u, z)+G(y, v, w)]
$$


and

$$
G(F(y, x), F(v, u), F(w, z)) \leq \frac{k}{2}[G(x, u, z)+G(y, v, w)]
$$

which implies that

$$
G(F(x, y), F(u, v), F(z, w))+G(F(y, x), F(v, u), F(w, z)) \leq k[G(x, u, z)+G(y, v, w)]
$$

that is,

$$
\Lambda(T(x, y), T(u, v), T(z, w)) \leq k \Lambda((x, y),(u, v),(z, w))
$$

for all $(x, y),(u, v),(z, w) \in Y$, where $\Lambda$ is defined in (70). From Lemma 4.1, since $(X, G)$ is G-complete, $(Y, \Lambda)$ is $\Lambda$-complete. In this case, regarding Theorem 2.1, we conclude that $T$ has a fixed point, which due to Lemma 4.1 implies that $F$ has a coupled fixed point.

Analogously, Theorem 4.3 is obtained from Theorem 2.2.

The following theorem can be derived easily from Theorem 4.1.

Theorem 4.3 Let $(X, G)$ be a G-complete G-metric space. Let $F: X \times X \rightarrow X$ be a mapping such that

$$
G(F(x, y), F(u, v), F(u, v)) \leq \frac{k}{2}(G(x, u, u)+G(y, v, v)) \quad \text { for all } x, y, u, v \in X .
$$

If $k \in[0,1)$, then there is a unique $x \in X$ such that $F(x, x)=x$.

We note that Theorem 4.3 above is not stated in [31].

Theorem 4.4 Theorem 4.3 follows from Theorem 2.2.

Example 4.1 Let $X=\mathbb{R}$. Define $G: X \times X \times X \rightarrow[0,+\infty)$ by

$$
G(x, y, z)=|x-y|+|x-z|+|y-z|
$$

for all $x, y, z \in X$. Then $(X, G)$ is a $G$-metric space. Define a map $F: X \times X \rightarrow X$ by $F(x, y)=$ $\frac{3}{5} x-\frac{1}{5} y$ for all $x, y \in X$. Then, for all $x, y, u, v, w, z \in X$ with $y=v=z$, we have

$$
\begin{aligned}
G(F(x, y), F(u, v), F(w, z)) & =G\left(\frac{3}{5} x-\frac{1}{5} y, \frac{3}{5} u-\frac{1}{5} v, \frac{3}{5} w-\frac{1}{5} z\right) \\
& =\frac{3}{5}[|x-u|+|x-w|+|u-w|]
\end{aligned}
$$

and

$$
G(x, u, w)+G(y, v, z)=|x-u|+|x-w|+|u-w| .
$$

Then it is easy to see that there is no $k \in[0,1)$ such that

$$
G(F(x, y), F(u, v), F(w, z)) \leq \frac{k}{2}[G(x, u, w)+G(y, v, z)]
$$


for all $x, y, u, v, z, w \in X$. Indeed, the inequality above holds for $k \geq \frac{6}{5}$. Thus, Theorem 4.1 does not apply to this example. However, it is easy to see that 0 is the unique point such that $F(0,0)=0$.

On the other hand, Theorem 2.1 yields the existence of the fixed point. Indeed,

$$
\begin{aligned}
\Lambda & (T(x, y), T(u, v), T(w, z)) \\
& =G(F(x, y), F(u, v), F(w, z))+G(F(y, x), F(v, u), F(z, w)) \\
& =G\left(\frac{3}{5} x-\frac{1}{5} y, \frac{3}{5} u-\frac{1}{5} v, \frac{3}{5} w-\frac{1}{5} z\right)+G\left(\frac{3}{5} y-\frac{1}{5} x, \frac{3}{5} v-\frac{1}{5} u, \frac{3}{5} z-\frac{1}{5} w\right) \\
& \leq \frac{4}{5}[(|x-u|+|x-w|+|u-w|)+(|y-v|+|y-z|+|v-z|)] \\
& =\frac{4}{5}[G(x, u, w)+G(y, v, z)] \\
& \leq k \Lambda((x, y),(u, v),(w, z)),
\end{aligned}
$$

where $k \in\left[\frac{4}{5}, 1\right)$. Thus, all conditions of Theorem 3.1 are satisfied, which guarantees the existence of the fixed point $F(0,0)=0$.

\subsection{Choudhury and Maity's coupled fixed point results in a G-metric space}

Choudhury and Maity [53] proved the following coupled fixed point theorems on ordered G-metric spaces.

Theorem 4.5 Let $(X, \preceq)$ be a partially ordered set and $G$ be a G-metric on $X$ such that $(X, G)$ is a complete $G$-metric space. Let $F: X \times X \rightarrow X$ be a G-continuous mapping having the mixed monotone property on $X$. Suppose that there exists a $k \in[0,1)$ such that

$$
G(F(x, y), F(u, v), F(w, z)) \leq \frac{k}{2}[G(x, u, w)+G(y, v, z)]
$$

for all $x, y, u, v, w, z \in X$ with $x \succeq u \succeq w$ and $y \preceq v \preceq z$, where either $u \neq w$ or $v \neq z$. If there exist $x_{0}, y_{0} \in X$ such that $x_{0} \preceq F\left(x_{0}, y_{0}\right)$ and $F\left(y_{0}, x_{0}\right) \preceq y_{0}$, then $F$ has a coupled fixed point, that is, there exists $(x, y) \in X \times X$ such that $x=F(x, y)$ and $y=F(y, x)$.

Theorem 4.6 If in the above theorem, instead of G-continuity of $F$, we assume that $X$ is ordered complete, then $F$ has a coupled fixed point.

We will prove the following result.

Theorem 4.7 Theorem 4.5 and Theorem 4.6 follow from Theorems 3.4 and 3.6, respectively.

Proof From (75), for all $(x, y),(u, v),(w, z) \in X \times X$ with $x \succeq u \succeq w$ and $y \preceq v \preceq z$, we have

$$
G(F(x, y), F(u, v), F(w, z)) \leq \frac{k}{2}[G(x, u, w)+G(y, v, z)]
$$

and

$$
G(F(y, x), F(v, u), F(z, w)) \leq \frac{k}{2}[G(x, u, w)+G(y, v, z)] .
$$


This implies that for all $(x, y),(u, v),(w, z) \in X \times X$ with $x \succeq u \succeq w$ and $y \preceq v \preceq z$,

$$
G(F(x, y), F(u, v), F(w, z))+G(F(y, x), F(v, u), F(z, w)) \leq k[G(x, u, w)+G(y, v, z)],
$$

that is,

$$
\Lambda(T(x, y), T(u, v), T(w, z)) \leq k \Lambda((x, y),(u, v),(w, z))
$$

for all $(x, y),(u, v),(w, z) \in Y$ with $(x, y) \succeq_{2}(u, v) \succeq_{2}(w, z)$, where $\Lambda$ is defined in (70).

It follows from Lemma 4.1 that since $(X, G)$ is $G$-complete, then $(Y, \Lambda)$ is $\Lambda$-complete. Since $F$ has the mixed monotone property, $T$ is a nondecreasing mapping with respect to $\preceq_{2}$. The assumption that there exist $x_{0}, y_{0} \in X$ such that $x_{0} \preceq F\left(x_{0}, y_{0}\right)$ and $F\left(y_{0}, x_{0}\right) \preceq y_{0}$ becomes $\left(x_{0}, y_{0}\right) \preceq_{2} T\left(x_{0}, y_{0}\right)$ in terms of the order $\preceq_{2}$. Now, if $F$ is $G$-continuous, then $T$ is $\Lambda$-continuous. In this case, applying Theorem 3.4, we get that $T$ has a fixed point, which due to Lemma 4.1 implies that $F$ has a coupled fixed point. If $X$ is ordered complete, then $Y$ satisfies the following property: if a nondecreasing (with respect to $\preceq_{2}$ ) sequence $\left\{u_{n}\right\}$ in $Y$ converges to some point $u \in Y$, then $u_{n} \preceq_{2} u$ for all $n$. Applying Theorem 3.6, we get that $T$ has a fixed point, that is, $F$ has a coupled fixed point.

Remark 4.1 (Uniqueness) If, in addition, we suppose that for all $(x, y),(u, v) \in X \times X$, there exists $\left(z_{1}, z_{2}\right) \in X \times X$ such that $(x, y) \preceq_{2}\left(z_{1}, z_{2}\right)$ and $(u, v) \preceq_{2}\left(z_{1}, z_{2}\right)$, from the last part of Theorems 3.4 and 3.6, we obtain the uniqueness of the fixed point of $T$, which implies the uniqueness of the coupled fixed point of $F$. Now, let $\left(x^{*}, y^{*}\right) \in X \times X$ be the unique coupled fixed point of $F$. Since $\left(y^{\prime \prime}, x^{\prime \prime}\right)$ is also a coupled fixed point of $F$, we get $x^{\prime \prime}=y^{\prime \prime}$.

\subsection{Coupled fixed point results of Aydi et al. in a G-metric space}

We consider the following fixed point theorems established by Aydi et al. [23]. The following lemma is trivial.

Lemma 4.2 (See [23]) Let $\phi \in \Psi$. For all $t>0$, we have $\lim _{n \rightarrow \infty} \phi^{n}(t)=0$.

Aydi et al. [17] proved the following fixed point theorems.

Theorem 4.8 Let $(X, \preceq)$ be a partially ordered set and $G$ be a G-metric on $X$ such that $(X, G)$ is a G-complete G-metric space. Suppose that there exist $\phi \in \Psi$ and $F: X \times X \rightarrow X$ such that

$$
G(F(x, y), F(u, v), F(w, z)) \leq \phi\left(\frac{G(x, u, w)+G(y, v, z)}{2}\right)
$$

for all $x, y, u, v, w, z \in X$ with $x \succeq u \succeq w$ and $y \preceq v \preceq z$. Suppose also that $F$ is G-continuous and has the mixed monotone property. If there exist $x_{0}, y_{0} \in X$ such that $x_{0} \preceq F\left(x_{0}, y_{0}\right)$ and $F\left(y_{0}, x_{0}\right) \preceq y_{0}$, then $F$ has a coupled fixed point, that is, there exists $(x, y) \in X \times X$ such that $x=F(x, y)$ and $y=F(y, x)$.

Replacing the $G$-continuity of $F$ by ordered completeness of $X$ yields the next theorem. 
Theorem 4.9 Let $(X, \preceq)$ be a partially ordered set and $G$ be a G-metric on $X$ such that $(X, G, \preceq)$ is G-complete. Suppose that there exist $\phi \in \Psi$ and $F: X \times X \rightarrow X$ such that

$$
G(F(x, y), F(u, v), F(w, z)) \leq \phi\left(\frac{G(x, u, w)+G(y, v, z)}{2}\right)
$$

for all $x, y, u, v, w, z \in X$ with $x \succeq u \succeq w$ and $y \preceq v \preceq z$. Suppose also that $F$ has the mixed monotone property and $X$ is ordered complete. If there exist $x_{0}, y_{0} \in X$ such that $x_{0} \preceq F\left(x_{0}, y_{0}\right)$ and $F\left(y_{0}, x_{0}\right) \preceq y_{0}$, then $F$ has a coupled fixed point, that is, there exists $(x, y) \in X \times X$ such that $x=F(x, y)$ and $y=F(y, x)$.

We will prove the following result.

Theorem 4.10 Theorem 4.8 and Theorem 4.9 follow from Theorems 3.9 and 3.10, respectively.

Proof From (76), for all $(x, y),(u, v),(w, z) \in X \times X$ with $x \succeq u \succeq w$ and $y \preceq v \preceq z$, we have

$$
G(F(x, y), F(u, v), F(w, z)) \leq \phi\left(\frac{G(x, u, w)+G(y, v, z)}{2}\right)
$$

and

$$
G(F(y, x), F(v, u), F(z, w)) \leq \phi\left(\frac{G(x, u, w)+G(y, u, z)}{2}\right) .
$$

This implies that for all $(x, y),(u, v),(w, z) \in X \times X$ with $x \succeq u \succeq w$ and $y \preceq v \preceq z$,

$$
\frac{G(F(x, y), F(u, v), F(w, z))+G(F(y, x), F(v, u), F(z, w))}{2} \leq \phi\left(\frac{G(x, u, w)+G(y, v, z)}{2}\right)
$$

holds. Rewrite the above inequality as

$$
\Lambda^{\prime}(T(x, y), T(u, v), T(w, z)) \leq \varphi\left(\Lambda^{\prime}((x, y),(u, v),(w, z))\right)
$$

for all $(x, y),(u, v),(w, z) \in Y$ with $(x, y) \succeq_{2}(u, v) \succeq_{2}(w, z)$. Here, $\Lambda^{\prime}: Y \times Y \times Y \rightarrow[0, \infty)$ is the $G$-metric on $Y$ defined by

$$
\Lambda^{\prime}((x, y),(u, v),(w, z))=\frac{\Lambda((x, y),(u, v),(w, z))}{2}, \quad \text { for all }(x, y),(u, v),(w, z) \in Y,
$$

where $\Lambda$ is given in (70). Thus, the mapping $T$ satisfies the conditions of Theorem 3.9 (resp. Theorem 3.10). Therefore, $T$ has a fixed point, which implies that $F$ has a coupled fixed point.

\subsection{On coupled fixed point results of Abbas et al. in a G-metric space}

Let $\Theta$ be the set of functions $\theta:[0, \infty)^{2} \rightarrow[0,1)$ which satisfy the condition

$$
\theta\left(s_{n}, t_{n}\right) \longrightarrow 1 \text { implies } t_{n}, s_{n} \longrightarrow 0
$$

The following theorems have been given by Abbas et al. [37]. 
Theorem 4.11 Let $(X, \preceq)$ be a partially ordered set and $G$ be a G-metric on X. Assume that there is an altering distance function $\theta \in \Theta$ and a map $F: X \times X \rightarrow X$ such that

$$
\begin{gathered}
G(F(x, y), F(u, v), F(w, z))+G(F(y, x), F(v, u), F(z, w)) \\
\quad \leq \theta(G(x, u, w), G(y, v, z))[G(x, u, w)+G(y, v, z)]
\end{gathered}
$$

for all $x, y, u, v, w, z \in X$ with $x \succeq u \succeq w$ and $y \preceq v \preceq z$. Suppose that $F$ is G-continuous and has the mixed monotone property. If there exist $x_{0}, y_{0} \in X$ such that $x_{0} \preceq F\left(x_{0}, y_{0}\right)$ and $F\left(y_{0}, x_{0}\right) \preceq y_{0}$, then $F$ has a coupled fixed point, that is, there exists $(x, y) \in X \times X$ such that $x=F(x, y)$ and $y=F(y, x)$.

Theorem 4.12 Let $(X, \preceq)$ be a partially ordered set and $G$ be a G-metric on $X$. Assume that there is an altering distance function $\theta \in \Theta$ and a mapping $F: X \times X \rightarrow X$ such that

$$
\begin{gathered}
G(F(x, y), F(u, v), F(w, z))+G(F(y, x), F(v, u), F(z, w)) \\
\quad \leq \theta(G(x, u, w), G(y, v, z))[G(x, u, w)+G(y, v, z)]
\end{gathered}
$$

for all $x, y, u, v, w, z \in X$ with $x \succeq u \geq w$ and $y \preceq v \preceq z$. Suppose that $F$ has the mixed monotone property and $X$ is ordered complete. If there exist $x_{0}, y_{0} \in X$ such that $x_{0} \preceq F\left(x_{0}, y_{0}\right)$ and $F\left(y_{0}, x_{0}\right) \preceq y_{0}$, then $F$ has a coupled fixed point, that is, there exists $(x, y) \in X \times X$ such that $x=F(x, y)$ and $y=F(y, x)$.

We will prove the following result.

Theorem 4.13 Theorem 4.11 and Theorem 4.12 follow from Theorem 3.11 and Theorem 3.12.

Proof From (78), for all $(x, y),(u, v),(w, z) \in X \times X$ with $x \succeq u \succeq w$ and $y \preceq v \preceq z$, we have

$$
\begin{gathered}
G(F(x, y), F(u, v), F(w, z))+G(F(y, x), F(v, u), F(z, w)) \\
\quad \leq \theta(G(x, u, w), G(y, v, z))[G(x, u, w)+G(y, v, z)] .
\end{gathered}
$$

This is equivalent to

$$
\Lambda(T(x, y), T(u, v), T(w, z)) \leq \beta(\Lambda((x, y),(u, v),(w, z))) \Lambda((x, y),(u, v),(w, z))
$$

for all $(x, y),(u, v),(z, w) \in Y$ with $(x, y) \succeq_{2}(u, v) \succeq_{2}(w, z)$, where $\theta(t, s)=\beta(t+s)$, which clearly implies that $\beta \in \mathcal{S}$.

From Lemma 4.1, since $(X, G)$ is $G$-complete, $(Y, \Lambda)$ is $\Lambda$-complete. Since $F$ has the mixed monotone property, $T$ is a nondecreasing mapping with respect to $\preceq_{2}$. According to the assumption of Theorem 4.11, we have $\left(x_{0}, y_{0}\right) \preceq_{2} T\left(x_{0}, y_{0}\right)$. Now, if $F$ is $G$-continuous, then $T$ is $\Lambda$-continuous. In this case, applying Theorem 3.11, we get that $T$ has a fixed point, which implies from Lemma 4.1 that $F$ has a coupled fixed point. If $X$ is ordered complete, then $Y$ satisfies the following property: if a nondecreasing (with respect to $\preceq_{2}$ ) then the sequence $\left\{u_{n}\right\}$ in $Y$ converges to some point $u \in Y$, then $u_{n} \preceq_{2} u$ for all $n$. Applying Theorem 3.12, we get that $T$ has a fixed point, which implies that $F$ has a coupled fixed point. 


\section{Remarks on common coupled fixed point theorems in G-metric spaces}

In this last section, we investigate the similarity between most of the common coupled fixed point theorems and ordinary fixed point theorems in the context of $G$-metric spaces and we show that the former are immediate consequences of the latter.

\subsection{Shatanawi's common coupled fixed point results in a G-metric space}

We start with two theorems by Shatanawi [31].

Theorem 5.1 (cf. [31]) Let $(X, G)$ be a G-metric space. Let $F: X \times X \rightarrow X$ and $g: X \rightarrow X$ be two mappings such that

$$
G(F(x, y), F(u, v), F(w, z)) \leq \frac{k}{2}(G(g x, g u, g w)+G(g y, g v, g z))
$$

for all $x, y, u, v, z, w \in X$. Assume that $F$ and $g$ satisfy the following conditions:

(1) $F(X \times X) \subset g(X)$,

(2) $g(X)$ is G-complete,

(3) $g$ is G-continuous and commutes with $F$.

If $k \in[0,1)$, then there is a unique $x \in X$ such that $g x=F(x, x)=x$.

Theorem 5.2 (cf. [31]) Let $(X, G)$ be a G-metric space. Let $F: X \times X \rightarrow X$ and $g: X \rightarrow X$ be two mappings such that

$$
G(F(x, y), F(u, v), F(u, v)) \leq \frac{k}{2}(G(g x, g u, g u)+G(g y, g \nu, g v))
$$

for all $x, y, u, v \in X$. Assume that $F$ and $g$ satisfy the following conditions:

(1) $F(X \times X) \subset g(X)$,

(2) $g(X)$ is G-complete,

(3) $g$ is G-continuous and commutes with $F$.

If $k \in[0,1)$, then there is a unique $x \in X$ such that $g x=F(x, x)=x$.

Theorem 5.3 Theorem 5.1 and Theorem 5.2 follow from Theorem 3.1 and Theorem 3.2, respectively.

Proof From (81), for all $(x, y),(u, v),(w, z) \in X \times X$, we have

$$
G(F(x, y), F(u, v), F(w, z)) \leq \frac{k}{2}[G(g x, g u, g w)+G(g y, g v, g z)],
$$

and

$$
G(F(y, x), F(v, u), F(z, w)) \leq \frac{k}{2}[G(g x, g u, g w)+G(g y, g v, g z)] .
$$

Therefore, for all $(x, y),(u, v),(w, z) \in X \times X$, we obtain

$$
\begin{aligned}
& G(F(x, y), F(u, v), F(w, z))+G(F(y, x), F(v, u), F(z, w)) \\
& \quad \leq k[G(g x, g u, g w)+G(g y, g v, g z)],
\end{aligned}
$$


that is,

$$
\Lambda\left(T_{F}(x, y), T_{F}(u, v), T_{F}(w, z)\right) \leq k \Lambda\left(T_{g}(x, y), T_{g}(u, v), T_{g}(w, z)\right)
$$

for all $(x, y),(u, v),(w, z) \in Y$, where $T_{F}, T_{g}: X^{2} \rightarrow X^{2}$ are mappings such that $T_{F}(a, b)=$ $(F(a, b), F(b, a))$ and $T_{g}(a, b)=(g a, g b)$ and $\Lambda$ is defined in (70). From Lemma 4.1, since $(X, G)$ is $G$-complete, $(Y, \Lambda)$ is $\Lambda$-complete. In this case, applying Theorem 3.1, we get that $T_{F}$ and $T_{g}$ have a common fixed point, which implies from Lemma 4.1 that $F$ and $g$ have a common coupled fixed point.

Analogously, Theorem 5.2 is obtained from Theorem 3.2.

Example 5.1 Let $X=\mathbb{R}$. Define $G: X \times X \times X \rightarrow[0,+\infty)$ by

$$
G(x, y, z)=|x-y|+|x-z|+|y-z|
$$

for all $x, y, z \in X$. Then $(X, G)$ is a $G$-metric space. Define a map $F: X \times X \rightarrow X$ by $F(x, y)=$ $\frac{4}{8} x-\frac{1}{8} y$ and $g: X \rightarrow X$ by $g(x)=\frac{7 x}{8}$ for all $x, y \in X$. Then, for all $x, y, u, v, z, w \in X$ with $y=v=z$, we have

$$
\begin{aligned}
G(F(x, y), F(u, v), F(w, z)) & =G\left(\frac{4}{8} x-\frac{1}{8} y, \frac{4}{8} u-\frac{1}{8} v, \frac{4}{8} w-\frac{1}{8} z\right) \\
& =\frac{4}{8}[|x-u|+|x-w|+|u-w|]
\end{aligned}
$$

and

$$
\begin{aligned}
G(g x, g u, g z)+G(g y, g \nu, g w) & =G\left(\frac{7 x}{8}, \frac{7 u}{8}, \frac{7 w}{8}\right)+G\left(\frac{7 y}{8}, \frac{7 v}{8}, \frac{7 z}{8}\right) \\
& =\frac{7}{8}[|x-u|+|x-w|+|u-w|] .
\end{aligned}
$$

Then it is easy to see that there is no $k \in[0,1)$ such that

$$
G(F(x, y), F(u, v), F(w, z)) \leq \frac{k}{2}[G(g x, g u, g w)+G(g y, g v, g z)]
$$

for all $x, y, u, v, z, w \in X$. Thus, Theorem 5.1 does not provide the existence of the common fixed point for the maps on this example. However, it is easy to see that 0 is the unique point $x \in X$ such that $x=g x=F(x, x)$.

On the other hand, notice that Theorem 3.1 yields the fixed point. Indeed,

$$
\begin{aligned}
\Lambda & \left(T_{F}(x, y), T_{F}(u, v), T_{F}(w, z)\right) \\
& =G(F(x, y), F(u, v), F(w, z))+G(F(y, x), F(v, u), F(z, w)) \\
& =G\left(\frac{4}{8} x-\frac{1}{8} y, \frac{4}{8} u-\frac{1}{8} v, \frac{4}{8} w-\frac{1}{8} z\right)+G\left(\frac{4}{8} y-\frac{1}{8} x, \frac{4}{8} v-\frac{1}{8} u, \frac{4}{8} z-\frac{1}{8} w\right) \\
& \leq \frac{5}{8}[(|x-u|+|x-z|+|u-z|)+(|y-v|+|y-w|+|v-w|)],
\end{aligned}
$$


and also

$$
\begin{aligned}
G(g x, g u, g w)+G(g y, g v, g z) & =G\left(\frac{7 x}{8}, \frac{7 u}{8}, \frac{7 w}{8}\right)+G\left(\frac{7 y}{8}, \frac{7 v}{8}, \frac{7 z}{8}\right) \\
& =\frac{7}{8}[|x-u|+|x-w|+|u-w|] .
\end{aligned}
$$

Then the condition (6) of Theorem 3.1 holds for $k \in\left[\frac{5}{7}, 1\right)$. Thus, all conditions of Theorem 3.1 are satisfied, which provides the common coupled fixed point of $F$ and $g$.

\subsection{Nashine's common coupled fixed point results in a G-metric space}

Nashine [54] studied common coupled fixed points on ordered G-metric spaces and proved the following theorems.

Theorem 5.4 Let $(X, G, \preceq)$ be a partially ordered $G$-metric space. Let $F: X \times X \rightarrow X$ and $g: X \rightarrow X$ be mappings such that $F$ has the mixed $g$-monotone property. Suppose that there exist $x_{0}, y_{0} \in X$ such that $g x_{0} \preceq F\left(x_{0}, y_{0}\right)$ and $F\left(y_{0}, x_{0}\right) \preceq g y_{0}$. Suppose also that there exists $k \in\left[0, \frac{1}{2}\right)$ such that

$$
G(F(x, y), F(u, v), F(w, z)) \leq k[G(g x, g u, g w)+G(g y, g v, g z)]
$$

holds for all $x, y, u, v, w, z \in X$ satisfying $g x \geq g u \succeq g w$ and $g y \preceq g v \preceq g z$, where either $g u \neq g z$ or $g v \neq g w$. We assume the following hypotheses:

(i) $F(X \times X) \subseteq g(X)$,

(ii) $F$ is G-continuous,

(iii) $g(X)$ is G-complete,

(iv) $g$ is G-continuous and commutes with $F$.

Then $F$ and $g$ have a coupled coincidence point, that is, there exists $(x, y) \in X \times X$ such that $g x=F(x, y)$ and $g y=F(y, x)$. If $g u=g z$ and $g v=g w$, then $F$ and $g$ have a common fixed point, that is, there exists $x \in X$ such that $g x=F(x, x)=x$.

Theorem 5.5 If in the above theorem we replace the G-continuity of $F$ by the assumption that $X$ is $g$-ordered complete, then $F$ and $g$ have a coupled coincidence point.

Theorem 5.6 Theorem 5.4 and Theorem 5.5 follow from Corollary 3.3 and Corollary 3.4, respectively.

Proof From (83), for all $(x, y),(u, v),(w, z) \in X \times X$ with $g x \succeq g u \succeq g w$ and $g y \preceq g v \preceq g z$, we have

$$
G(F(x, y), F(u, v), F(w, z)) \leq \frac{k}{2}[G(g x, g u, g w)+G(g y, g v, g z)]
$$

and

$$
G(F(y, x), F(v, u), F(z, w)) \leq \frac{k}{2}[G(g x, g u, g w)+G(g y, g v, g z)] .
$$

This implies that for all $(x, y),(u, v),(z, w) \in X \times X$ with $g x \succeq g u \succeq g w$ and $g y \preceq g v \preceq g z$,

$$
G(F(x, y), F(u, v), F(w, z))+G(F(y, x), F(v, u), F(z, w)) \leq k[G(g x, g u, g w)+G(g y, g v, g z)],
$$


that is,

$$
\Lambda(T(x, y), T(u, v), T(w, z)) \leq k \Lambda((g x, g y),(g u, g v),(g z, g w))
$$

for all $(x, y),(u, v),(z, w) \in Y$ with $(g x, g y) \succeq_{2}(g u, g v) \succeq_{2}(g w, g z)$.

From Lemma 4.1, since $(X, G)$ is $G$-complete, $(Y, \Lambda)$ is $\Lambda$-complete. Also, since $F$ has the mixed $g$-monotone property, $T$ is a $g$-nondecreasing mapping with respect to $\preceq_{2}$. From the assumption of Theorem 5.4, we have $\left(g x_{0}, g y_{0}\right) \preceq_{2} T\left(x_{0}, y_{0}\right)$. Now, if $F$ is $G$-continuous, then $T$ is $\Lambda$-continuous. In this case, due to Corollary 3.3, we deduce that $T$ and $g$ have a coincidence point, which from Lemma 4.1 implies that $F$ and $g$ have a coupled coincidence point. If, on the other hand, $X$ is $g$-ordered complete, then $Y$ satisfies the following property: if a nondecreasing (with respect to $\preceq_{2}$ ) sequence $\left\{u_{n}\right\}$ in $Y$ converges to a point $u \in Y$, then $u_{n} \preceq_{2} u$ for all $n$. According to Corollary 3.4, $T$ and $g$ have a coincidence point, which from Lemma 4.1 implies that $F$ and $g$ have a coupled coincidence point.

\subsection{Common coupled fixed point results of Aydi et al. in a G-metric space}

Recently, Aydi et al. [17] proved the following theorems on G-metric spaces.

Theorem 5.7 Let $(X, \preceq)$ be a partially ordered set and $G$ be a G-metric on $X$ such that $(X, G)$ is a G-complete G-metric space. Suppose that there exist maps $\phi \in \Psi$ and $F: X \times$ $X \rightarrow X$ and $g: X \rightarrow X$ such that

$$
G(F(x, y), F(u, v), F(w, z)) \leq \phi\left(\frac{G(g x, g u, g w)+G(g y, g v, g z)}{2}\right)
$$

for all $x, y, u, v, w, z \in X$ with $g x \succeq g u \geq g w$ and $g y \preceq g v \preceq g z$. Suppose also that $F$ is G-continuous and has the mixed g-monotone property, $F(X \times X) \subset g(X)$, and $g$ is $G$ continuous and commutes with $F$. If there exist $x_{0}, y_{0} \in X$ such that $g x_{0} \preceq F\left(x_{0}, y_{0}\right)$ and $F\left(y_{0}, x_{0}\right) \preceq g y_{0}$, then $F$ and $g$ have a coupled coincidence point, that is, there exists $(x, y) \in$ $X \times X$ such that $g x=F(x, y)$ and $g y=F(y, x)$.

Theorem 5.8 Let $(X, \preceq)$ be a partially ordered set and $G$ be a G-metric on $X$ such that $(X, G, \preceq)$ is $G$-complete. Suppose that there exist $\phi \in \Psi$ and $F: X \times X \rightarrow X$ and $g: X \rightarrow X$ such that

$$
G(F(x, y), F(u, v), F(w, z)) \leq \phi\left(\frac{G(g x, g u, g w)+G(g y, g v, g z)}{2}\right)
$$

for all $x, y, u, v, w, z \in X$ with $g x \geq g u \geq g w$ and $g y \preceq g v \preceq g z$. Suppose also that $X$ is $g$ ordered complete and $F$ has the mixed $g$-monotone property, $F(X \times X) \subset g(X)$, and $g$ is $G$-continuous and commutes with $F$. If there exist $x_{0}, y_{0} \in X$ such that $g x_{0} \preceq F\left(x_{0}, y_{0}\right)$ and $F\left(y_{0}, x_{0}\right) \preceq g y_{0}$, then $F$ and $g$ have a coupled coincidence point, that is, there exists $(x, y) \in$ $X \times X$ such that $g x=F(x, y)$ and $g y=F(y, x)$.

The following result can be also proved easily.

Theorem 5.9 Theorem 4.8 and Theorem 4.9 follow from Theorems 3.7 and 3.8. 
Proof We observe from (84) that for all $(x, y),(u, v),(w, z) \in X \times X$ with $g x \succeq g u \succeq g w$ and $g y \preceq g v \preceq g z$, we have

$$
G(F(x, y), F(u, v), F(w, z)) \leq \phi\left(\frac{G(g x, g u, g w)+G(g y, g v, g z)}{2}\right),
$$

and also

$$
G(F(y, x), F(v, u), F(z, w)) \leq \phi\left(\frac{G(g x, g u, g w)+G(g y, g v, g z)}{2}\right) .
$$

Therefore, for all $(x, y),(u, v),(w, z) \in X \times X$ with $g x \succeq g u \succeq g w$ and $g y \preceq g v \preceq g z$, the following inequality holds:

$$
\begin{aligned}
& \frac{G(F(x, y), F(u, v), F(w, z))+G(F(y, x), F(v, u), F(z, w))}{2} \\
& \quad \leq \phi\left(\frac{G(g x, g u, g w)+G(g y, g v, g z)}{2}\right)
\end{aligned}
$$

that is,

$$
\Lambda^{\prime}\left(T_{F}(x, y), T_{F}(u, v), T_{F}(w, z)\right) \leq \varphi\left(\Lambda^{\prime}\left(T_{g}(x, y), T_{g}(u, v), T_{g}(w, z)\right)\right)
$$

for all $(x, y),(u, v),(w, z) \in Y$ with $(x, y) \succeq_{2}(u, v) \succeq_{2}(w, z)$, where $T_{F}, T_{g}: X^{2} \rightarrow X^{2}$ are mappings such that $T_{F}(a, b)=(F(a, b), F(b, a))$ and $T_{g}(a, b)=(g a, g b)$. Note that here, $\Lambda^{\prime}: Y \times Y \times Y \rightarrow[0, \infty)$ is a $G$-metric on $Y$ defined by

$$
\Lambda^{\prime}((x, y),(u, v),(w, z))=\frac{\Lambda((x, y),(u, v),(w, z))}{2} \text { for all }(x, y),(u, v),(w, z) \in Y .
$$

Thus, we proved that the mappings $T_{F}$ and $T_{g}$ satisfy the conditions of Theorem 3.7 (resp. Theorem 3.8). Hence, $T_{F}$ and $T_{g}$ have a coincidence point, which implies that $F$ and $g$ have a coupled coincidence point.

\subsection{Common coupled fixed point results of Cho et al. in a G-metric space}

Finally, we consider the results of Cho et al. [55]. We state their fixed point theorems below.

Theorem 5.10 Let $(X, \preceq)$ be a partially ordered set and $G$ be a $G$-metric on $X$ such that $(X, G)$ is a G-complete G-metric space. Let $F: X \times X \rightarrow X$ and $g: X \rightarrow X$ be G-continuous mappings such that $F$ has the mixed $g$-monotone property and $g$ commutes with $F$. Assume that there exist altering distance functions $\phi$ and $\psi$ such that

$$
\begin{aligned}
\psi(G(F(x, y), F(u, v), F(w, z))) \leq & \psi(\max \{G(g x, g u, g w), G(g y, g v, g z)\}) \\
& -\phi(\max \{G(g x, g u, g w), G(g y, g v, g z)\})
\end{aligned}
$$

for all $x, y, u, v, w, z \in X$ with $g x \succeq g u \succeq g w$ and $g y \preceq g v \preceq g z$. Suppose also that $F(X \times X) \subseteq$ $g(X)$. If there exist $x_{0}, y_{0} \in X$ such that $g x_{0} \preceq F\left(x_{0}, y_{0}\right)$ and $F\left(y_{0}, x_{0}\right) \preceq g y_{0}$, then $F$ and $g$ have a coupled coincidence point, that is, there exists $(x, y) \in X \times X$ such that $g x=F(x, y)$ and $g y=F(y, x)$. 
Theorem 5.11 Let $(X, \preceq)$ be a partially ordered set and $G$ be a G-metric on $X$ and let $F: X \times X \rightarrow X$ and $g: X \rightarrow X$ be mappings. Assume that there exist altering distance functions $\phi$ and $\psi$ such that

$$
\begin{aligned}
\psi(G(F(x, y), F(u, v), F(w, z))) \leq & \psi(\max \{G(g x, g u, g w), G(g y, g v, g z)\}) \\
& -\phi(\max \{G(g x, g u, g w), G(g y, g v, g z)\})
\end{aligned}
$$

for all $x, y, u, v, w, z \in X$ with $g x \geq g u \succeq g w$ and $g y \preceq g v \preceq g z$. Suppose that $g(X)$ is $G$ complete, the mapping $F$ has the mixed $g$-monotone property and $F(X \times X) \subseteq g(X)$. If there exist $x_{0}, y_{0} \in X$ such that $g x_{0} \preceq F\left(x_{0}, y_{0}\right)$ and $F\left(y_{0}, x_{0}\right) \preceq g y_{0}$, then $F$ and $g$ have a coupled coincidence point, that is, there exists $(x, y) \in X \times X$ such that $g x=F(x, y)$ and $g y=F(y, x)$.

Theorem 5.12 Theorem 5.10 and Theorem 5.11 follow from Theorems 3.7 and 3.8.

Proof From the assumption, for all $(x, y),(u, v),(z, w) \in X \times X$ with $g x \succeq g u \succeq g w$ and $g y \preceq$ $g v \succeq g z$, we have

$$
\begin{aligned}
\psi(G(F(x, y), F(u, v), F(w, z))) \leq & \psi(\max \{G(g x, g u, g w), G(g y, g v, g z)\}) \\
& -\phi(\max \{G(g x, g u, g w), G(g y, g v, g z)\})
\end{aligned}
$$

and

$$
\begin{aligned}
\psi(G(F(y, x), F(v, u), F(z, w))) \leq & \psi(\max \{G(g x, g u, g w), G(g y, g \nu, g z)\}) \\
& -\phi(\max \{G(g x, g u, g w), G(g y, g v, g z)\}) .
\end{aligned}
$$

This implies (since $\psi$ is nondecreasing) that for all $(x, y),(u, v),(z, w) \in X \times X$ with $g x \succeq$ $g u \succeq g w$ and $g y \preceq g v \preceq g w$, we have

$$
\begin{aligned}
& \psi(\max \{G(F(x, y), F(u, v), F(w, z)), G(F(y, x), F(v, u), F(z, w))\}) \\
& \quad \leq \psi(\max \{G(g x, g u, g w), G(g y, g v, g z)\})-\varphi(\max \{G(g x, g u, g w), G(g y, g v, g z)\}),
\end{aligned}
$$

that is,

$$
\begin{aligned}
\psi\left(\Delta\left(T_{F}(x, y), T_{F}(u, v), T_{F}(z, w)\right)\right) \leq & \psi\left(\Delta\left(T_{g}(x, y), T_{g}(u, v), T_{g}(z, w)\right)\right) \\
& -\varphi\left(\Delta\left(T_{g}(x, y), T_{g}(u, v), T_{g}(z, w)\right)\right)
\end{aligned}
$$

for all $(x, y),(u, v),(z, w) \in Y$ with $(g x, g y) \succeq_{2}(g u, g v) \succeq_{2}(g z, g w)$, where $T_{F}, T_{g}: X^{2} \rightarrow X^{2}$ such that $T_{F}(a, b)=(F(a, b), F(b, a))$ and $T_{g}(a, b)=(g a, g b)$ and $\Delta$ is a $G$-metric defined in (71). Regarding Theorem 3.13, the conditions (90) and (32) of Theorem 3.7 are equivalent. Therefore, the mappings $T_{F}$ and $T_{g}$ satisfy the conditions of Theorem 3.7 (resp. Theorem 3.8) and have a coincidence point. Hence, the maps $F$ and $g$ have a coupled coincidence point. 


\section{Competing interests}

The authors declare that they have no competing interests.

\section{Authors' contributions}

All authors read and approved the final manuscript.

\section{Author details}

1 Department of Mathematics, Texas A\&M University-Kingsville, Kingsville, TX 78363, USA. ${ }^{2}$ Department of Mathematics, Faculty of Science, King Abdulaziz University, Jeddah, 21589, Saudi Arabia. ${ }^{3}$ Department of Mathematics, Atilim University, Incek, Ankara, 06836, Turkey.

\section{Received: 6 August 2012 Accepted: 5 December 2012 Published: 3 January 2013}

\section{References}

1. Banach, S: Sur les opérations dans les ensembles abstraits et leur application aux équations intégrales. Fundam. Math. 3, 133-181 (1922)

2. Ćirić, L, Agarwal, RP, Samet, B: Mixed monotone-generalized contractions in partially ordered probabilistic metric spaces. Fixed Point Theory Appl. 2011, 56 (2011)

3. Fenwick, DH, Batycky, RP: Using metric space methods to analyse reservoir uncertainty. In: Proceedings of the 2011 Gussow Conference, Banff, Alberta, Canada (2011)

4. Harjani, J, Sadarangani, K: Generalized contractions in partially ordered metric spaces and applications to ordinary differential equations. Nonlinear Anal. 72, 1188-1197 (2010)

5. Harjani, J, López, B, Sadarangani, K: Fixed point theorems for mixed monotone operators and applications to integral equations. Nonlinear Anal. 74, 1749-1760 (2011)

6. Matthews, SG: Partial metric topology. Research report 212, Dept. of Computer Science, University of Warwick (1992)

7. Mustafa, Z, Sims, B: A new approach to generalized metric spaces. J. Nonlinear Convex Anal. 7(2), 289-297 (2006)

8. Aydi, H, Karapınar, E, Shatanawi, W: Tripled fixed point results in generalized metric spaces. J. Appl. Math. 2012 Article ID 314279 (2012)

9. Ding, H-S, Karapınar, E: A note on some coupled fixed point theorems on G-metric space (submitted)

10. Mustafa, Z, Aydi, H, Karapınar, E: On common fixed points in G-metric spaces using (E.A) property. Comput. Math. Appl. (2012). doi:10.1016/j.camwa.2012.03.051

11. Mustafa, Z, Obiedat, H, Awawdeh, F: Some fixed point theorem for mapping on complete G-metric spaces. Fixed Point Theory Appl. 2008, Article ID 189870 (2008)

12. Mustafa, Z, Khandaqji, M, Shatanawi, W: Fixed point results on complete G-metric spaces. Studia Sci. Math. Hung. 48, 304-319 (2011)

13. Mustafa, Z, Sims, B: Fixed point theorems for contractive mappings in complete G-metric spaces. Fixed Point Theory Appl. 2009, Article ID 917175 (2009)

14. Mustafa, Z, Shatanawi, W, Bataineh, M: Existence of fixed point results in G-metric spaces. Int. J. Math. Math. Sci. 2009, Article ID 283028 (2009)

15. Shatanawi, W: Coupled fixed point theorems in generalized metric spaces. Hacet. J. Math. Stat. 40(3), 441-447 (2011)

16. Ran, ACM, Reurings, MCB: A fixed point theorem in partially ordered sets and some applications to matrix equations. Proc. Am. Math. Soc. 132, 1435-1443 (2004)

17. Aydi, H, Damjanović, B, Samet, B, Shatanawi, W: Coupled fixed point theorems for nonlinear contractions in partially ordered G-metric spaces. Math. Comput. Model. 54, 2443-2450 (2011)

18. Berinde, $\mathrm{V}$ : Generalized coupled fixed point theorems for mixed monotone mappings in partially ordered metric spaces. Nonlinear Anal. 74, 7347-7355 (2011)

19. Berinde, V: Coupled fixed point theorems for $\Phi$-contractive mixed monotone mappings in partially ordered metric spaces. Nonlinear Anal. 75, 3218-3228 (2012)

20. Berinde, V: Coupled coincidence point theorems for mixed monotone nonlinear operators. Comput. Math. Appl. (2012). doi:10.1016/j.camwa.2012.02.012

21. Choudhury, BS, Kundu, A: A coupled coincidence point result in partially ordered metric spaces for compatible mappings. Nonlinear Anal. 73, 2524-2531 (2010)

22. Gnana-Bhaskar, T, Lakshmikantham, V: Fixed point theorems in partially ordered metric spaces and applications. Nonlinear Anal. 65, 1379-1393 (2006)

23. Ćirić, L, Lakshmikantham, V: Coupled fixed point theorems for nonlinear contractions in partially ordered metric spaces. Nonlinear Anal. 70, 4341-4349 (2009)

24. Karapınar, E, Van Luong, N, Thuan, NX, Hai, TT: Coupled coincidence points for mixed monotone operators in partially ordered metric spaces. Arab. J. Math. (2012) (in press)

25. Karapınar, E: Coupled fixed point theorems for nonlinear contractions in cone metric spaces. Comput. Math. Appl. 59, 3656-3668 (2010)

26. Karapınar, E: Couple fixed point on cone metric spaces. Gazi Uni. J. Sci. 24, 51-58 (2011)

27. Luong, NV, Thuan, NX: Coupled fixed point theorems in partially ordered G-metric spaces. Math. Comput. Model. 55, 1601-1609 (2012)

28. Ding, H-S, Li, L: Coupled fixed point theorems in partially ordered cone metric spaces. Filomat 25(2), 137-149 (2011). doi:10.2298/FIL1102137D

29. Shatanawi, W: Fixed point theory for contractive mappings satisfying $\Phi$-maps in G-metric spaces. Fixed Point Theory Appl. 2010, Article ID 181650 (2010)

30. Shatanawi, W: Some fixed point theorems in ordered G-metric spaces and applications. Abstr. Appl. Anal. 2011 Article ID 126205 (2011)

31. Shatanawi, W: Coupled fixed point theorems in generalized metric spaces. Hacet. J. Math. Stat. 40(3), 441-447 (2011)

32. Shatanawi, W, Abbas, M, Nazir, T: Common coupled coincidence and coupled fixed point results in two generalized metric spaces. Fixed Point Theory Appl. 2011, 80 (2011) 
33. Tahat, N, Aydi, H, Karapınar, E, Shatanawi, W: Common fixed points for single-valued and multi-valued maps satisfying a generalized contraction in G-metric spaces. Fixed Point Theory Appl. 2012, 48 (2012)

34. Sintunavarat, W, Cho, YJ, Kumam, P: Common fixed point theorems for c-distance in ordered cone metric spaces. Comput. Math. Appl. 62, 1969-1978 (2011)

35. Mongkolkeha, C, Kumam, P: Best proximity point theorems for generalized cyclic contractions in ordered metric spaces. J. Optim. Theory Appl. (2012). doi:10.1007/s10957-012-9991-y

36. Guo, D, Lakshmikantham, V: Coupled fixed points of nonlinear operators with applications. Nonlinear Anal., Theory Methods Appl. 11, 623-632 (1987)

37. Abbas, M, Sintunavarat, W, Kumam, P: Coupled fixed point of generalized contractive mappings on partially ordered G-metric spaces. Fixed Point Theory Appl. 2012, 31 (2012)

38. Sintunavarat, W, Cho, YJ, Kumam, P: Coupled coincidence point theorems for contractions without commutative condition in intuitionistic fuzzy normed spaces. Fixed Point Theory Appl. 2011, 81 (2011)

39. Sintunavarat, W, Cho, YJ, Kumam, P: Coupled fixed point theorems for weak contraction mapping under F-invariant set. Abstr. Appl. Anal. 2012, Article ID 324874 (2012)

40. Sintunavarat, W, Kumam, P: Coupled best proximity point theorem in metric spaces. Fixed Point Theory Appl. 2012, $93(2012)$

41. Sintunavarat, $\mathrm{W}, \mathrm{Cho}, \mathrm{YJ}, \mathrm{Kumam}, \mathrm{P}$ : Coupled fixed-point theorems for contraction mapping induced by cone ball-metric in partially ordered spaces. Fixed Point Theory Appl. 2012, 128 (2012)

42. Sintunavarat, W, Petruşel, A, Kumam, P: Common coupled fixed point theorems for $W^{*}$-compatible mappings without mixed monotone property. Rend. Circ. Mat. Palermo. (2012). doi:10.1007/s12215-012-0096-0

43. Karapınar, E: Coupled fixed point theorems for nonlinear contractions in cone metric spaces. Comput. Math. Appl. 59 3656-3668 (2010)

44. Luong, NV, Thuan, NX: Coupled fixed point theorems in partially ordered metric spaces depended on another function. Bull. Math. Anal. Appl. 3(3), 129-140 (2011)

45. Rasouli, $\mathrm{SH}$, Bahrampour, $\mathrm{M}$ : A remark on the coupled fixed point theorems for mixed monotone operators in partially ordered metric spaces. J. Math. Comput. Sci. 3(2), 246-261 (2011)

46. Samet, B: Coupled fixed point theorems for a generalized Meir-Keeler contraction in partially ordered metric spaces. Nonlinear Anal. 74, 4508-4517 (2010)

47. Samet, B, Yazidi, H: Coupled fixed point theorems in partially ordered $\varepsilon$-chainable metric spaces. J. Math. Comput. Sci. 1(3), 142-151 (2010)

48. Mustafa, Z: A new structure for generalized metric spaces with applications to fixed point theory. Ph.D. Thesis, The University of Newcastle, Australia (2005)

49. Nieto, JJ, Rodríguez-López, R: Contractive mapping theorems in partially ordered sets and applications to ordinary differential equations. Order 22, 223-239 (2005)

50. Ćirić, L, Cakić, N, Rajović, M, Ume, JS: Monotone generalized nonlinear contractions in partially ordered metric spaces. Fixed Point Theory Appl. 2008, Article ID 131294 (2008)

51. Jachymski, J, Jóźwik, I: Nonlinear contractive conditions: a comparison and related problems. Fixed Point Theory Appl. Polish Acad. Sci. 77, 123-146 (2007)

52. Jachymski, J: Equivalent conditions for generalized contractions on (ordered) metric spaces. Nonlinear Anal. 74(3), 768-774 (2011)

53. Choudhury, BS, Maity, P: Coupled fixed point results in generalized metric spaces. Math. Comput. Model. 54, 73-79 (2011)

54. Nashine, HK: Coupled common fixed point results in ordered G-metric spaces. J. Nonlinear Sci. Appl. 1, 1-13 (2012)

55. Cho, YJ, Rhoades, BE, Saadati, R, Samet, B, Shatanawi, W: Nonlinear coupled fixed point theorems in ordered generalized metric spaces with integral type. Fixed Point Theory Appl. 2012, 8 (2012)

doi:10.1186/1687-1812-2013-2

Cite this article as: Agarwal and Karapınar: Remarks on some coupled fixed point theorems in G-metric spaces. Fixed Point Theory and Applications 2013 2013:0

\section{Submit your manuscript to a SpringerOpen ${ }^{\circ}$ journal and benefit from:}

- Convenient online submission

- Rigorous peer review

- Immediate publication on acceptance

- Open access: articles freely available online

- High visibility within the field

- Retaining the copyright to your article 